\title{
NACIMIENTO DE UNA INSTITUCIÓN COLEGIAL: EL COLEGIO DE ABOGADOS DE LOGROÑO ENTRE I838 Y I895
}

\author{
Isabel MARTÍNEZ NAVAS \\ Profesora Titular de Historia del Derecho \\ UNIVERSIDAD DE LA RIOJA
}

Sumario: I. El Colegio de Abogados De Logroño (I838-I895). I.I. Establecimiento del Colegio de Abogados de Logroño y primeros pasos. I.2. Estructura y organización del Colegio. I.2.I. La Junta General del Colegio de Abogados de Logroño. I.2.2. La Junta de Gobierno del Colegio de Abogados de Logroño. I.2.3. Los primeros decanos. I.2.4. Diputados, tesoreros, secretarios y personal al servicio del Colegio. I.3. Funcionamiento del Colegio. I.3.I. La inscripción colegial. I.3.2. La Abogacía de pobres. I.3.3. Otras cuestiones tocantes al funcionamiento del Colegio. II. Relación de colegiados (I838-1895).

Resumen: Los Estatutos de los Colegios de Abogados del Reino, de 5 de mayo de I838, dieron lugar al nacimiento de nuevas corporaciones de letrados en la totalidad de las capitales de provincia o localidades de asiento de Audiencias y Juzgados. En este contexto, doce abogados de la capital riojana constituyeron poco después el Colegio de Abogados de Logroño. El presente estudio constituye una primera aproximación a la génesis y primera andadura del Ilustre Colegio de Abogados de La Rioja.

PALABRAS ClAVE: Administración corporativa, corporativismo curial, abogados, Colegio de Abogados de Logroño.

ABSTRACT: The Regulations of the Bar Associations of the Spanish Kingdom, 5 May I838, gave way to the birth of new attorney corporations in every provincial capital or town where Courts and Tribunals were established. In this context, twelve lawyers of the capital of La Rioja constituted the Colegio de Abogados de Logroño a bit later. The present study is a first approximation to the genesis and first stages of the Ilustre Colegio de Abogados de La Rioja.

KEYWORDS: Corporate administration, curial corporate spirit, lawyers, bar associations.

En el próximo mes de mayo se cumplirán ciento setenta y cinco años de la publicación del real decreto por el que se aprobaron los Estatutos de los Colegios de Abogados del Reino, generalizándose a partir de los mismos la creación de nuevas corporaciones de letrados. En las siguientes páginas, se pretende realizar una primera aproximación a la génesis y evolución de uno de estos Colegios durante el período que puede considerarse 
como la primera andadura de la corporación, esto es, en el tiempo de vigencia de los mencionados Estatutos aprobados en I838, modificados en I895'.

La historia interna de las corporaciones curiales establecidas en diferentes puntos de España desde el siglo XIV ha sido objeto de atención más o menos detenida, en la mayor parte de los casos en relación directa con el nivel de conservación de la documentación generada por la institución colegial desde su establecimiento ${ }^{2}$. En este sentido, la escasa atención prestada al Colegio de Abogados instalado en la capital riojana, se debe, sin duda, a los escasos fondos documentales conservados en el archivo de la propia corporación, entre los que se encuentran las actas de sus órganos de gobierno y algunos libros sobre el turno de oficio, en tanto parece haberse perdido con el paso del tiempo otro tipo de documentación generada por el Colegio o recibida por éste, que habría resultado de gran interés para conocer la actividad desarrollada por los abogados logroñeses. Me refiero, fundamentalmente, a los informes, dictámenes o proyectos de reglamentos en los que participó el Colegio o alguno de sus miembros y cuya existencia consta por la referencia a los mismos en las actas de las juntas colegiales, pero de los que no se conserva ninguna copia en el exiguo archivo del Ilustre Colegio de Abogados de La Rioja. Con todo, la situación de partida a la hora de abordar un estudio detenido del desarrollo de esta institución desde su establecimiento hasta la actualidad, no resulta tan desalentadora como en relación a otras corporaciones, de las que no han conservado las actas de sus órganos de gobierno. En nuestro caso, la principal laguna documental afecta a la primera mitad del siglo XIX, período para el que no se conservan las actas de las Juntas Generales. Ese importante obstáculo podrá salvarse recurriendo a otro tipo de fondos documentales. Principalmente, a las noticias proporcionadas por la prensa, la documentación municipal o los estudios sobre la sociedad y la vida cultural riojana desde el establecimiento de la provincia de Logroño, así como con las noticias directas acerca de la actividad profesional de los letrados riojanos que nos proporcionan las demandas, los escritos de alegaciones, los procesos y las sentencias dictadas por los tribunales ante los que actúan aquellos, que en alguna medida se han conservado entre los fondos documentales de la Audiencia provincial de Logroño, del Juzgado municipal de la ciudad y de la Audiencia territorial de Burgos ${ }^{3}$. En todo caso, en el presente estudio -que, como antes apunté, no pretende ser más que una primera aproximación a la historia del Colegio de Abogados de La Rioja- me he servido casi exclusivamente de las fuentes directas conservadas en el archivo del Colegio, que permiten acercarse a las principales ocupaciones de sus primeros integrantes durante el primer medio siglo de existencia del Colegio de Abogados de Logroño.

\section{El Colegio de Abogados de Logroño (1838-1895)}

Con anterioridad al mes de agosto de 1838 no consta noticia alguna acerca de la existencia de asociaciones o corporaciones de letrados en la localidad de Logroño, lo que nos lleva a considerar que los abogados riojanos, a diferencia de sus colegas de otros puntos de España, desarrollaban su actividad profesional en un marco de absoluta independencia, sin que se hubiesen establecido vínculos corporativos de ningún tipo antes de la constitución del Colegio de Abogados de Logroño, en el verano de i838. A tenor de los datos contenidos

\footnotetext{
${ }^{\text {I }}$ El trabajo se enmarca así dentro de un estudio más ambicioso, también en lo que se refiere al período objeto de análisis, que llevo a cabo con el patrocinio del Ilustre Colegio de Abogados de La Rioja.

${ }^{2}$ La bibliografía sobre los diferentes Colegios de Abogados de España es muy numerosa y de desigual interés. Sin duda merecen especial consideración, entre otros, los trabajos sobre el Colegio de Abogados de Madrid y los que se refieren al de Valencia o al de Barcelona, de los que me he servido para la elaboración de este estudio.

${ }^{3}$ Convengo con M. PESET en que resulta imprescindible la consulta de estas otras fuentes para reconstruir una historia institucional que vaya más allá de la yuxtaposición de referencias normativas. En este sentido, en «Prólogo» a TORMO CAMALLONGA, C., El Colegio de Abogados de Valencia. Entre el Antiguo Régimen y el Liberalismo, Valencia, Universitat de València, 2004, pp. II-27,
} 
en el Censo de Floridablanca, el número de abogados «instalados» en Logroño en I787 era de nueve, elevándose hasta el centenar el de los establecidos en el conjunto de poblaciones que conforman la actual provincia de La Rioja ${ }^{4}$. Tanto Logroño como el conjunto de la provincia habrían mantenido un número muy similar de abogados desde la mitad del siglo XVIII y hasta bien avanzado el siglo XIX, con cifras que oscilan para la capital entre los cuatro y los doce y que se elevan a veinticinco y hasta casi el medio centenar en los años centrales del siglo XIX, descendiendo nuevamente en los años setenta ${ }^{5}$. Sin duda resulta determinante del reducido número de letrados radicados en la capital riojana el hecho de que no se contase en ese tiempo con Tribunales superiores establecidos en la provincia, debiéndose aguardar hasta 1883 para asistir a la instalación de una Audiencia de lo Criminal en la ciudad de Logroño. De esta forma, los abogados oriundos de La Rioja, que se formaban en este tiempo en las Universidades de Zaragoza, Valladolid, Alcalá, o en la propia Corte, se instalaban en su mayoría en Madrid, o en otras ciudades en las que tuviera su sede una Audiencia. Por su parte, aquellos que decidían permanecer en sus lugares de origen, podían encontrar acomodo como letrados en alguna de las instituciones locales Ayuntamiento, Diputación Provincial, Tribunal del Santo Oficio de la Inquisición con sede en Logroño, etc.- o bien abrir su propio bufete y ejercer la profesión en Logroño ${ }^{6}$. Estos últimos -como se ha apuntado antes- eran poco más de una decena en el tiempo en que tiene lugar el restablecimiento de la provincia de $\operatorname{Logroño}^{7}$ y la creación de la Audiencia Territorial de Burgos, a la que se asigna la provincia de Logroño ${ }^{8}$. Un tiempo también en el que las Cortes, tras consagrar el principio de libertad de ejercicio profesional ${ }^{9}$, apuestan decididamente por hacer compatible aquel derecho con la reconocida existencia de unos

${ }^{4}$ El Censo de I787 incluye a un total de IO2 abogados en La Rioja. Lógicamente, el mayor número se concentra en los núcleos más populosos, como Calahorra o Nájera, que cuentan con 8 abogados censados cada una de ellas, resultando significativo el dato de los 7 registrados en la localidad de Nalda, en tanto Haro, Arnedo o Santo Domingo de la Calzada incluyen en su censo de población un total de 4 abogados. Todos los datos de clasificación por ocupaciones, en Censo de 1787 «Floridablanca». La Rioja, Madrid, Instituto Nacional de Estadística, I987, pp. I865-1876.

${ }^{5}$ Según los datos contenidos en el Catastro del marqués de la Ensenada, en Logroño, en I75I, aparecen registrados cuatro abogados. Seis son los recogidos en el Vecindario de I770, ocho los que figuran en el Recuento de I773, doce los del Apeo de I8I8 y nueve los incluidos en el Censo de I836, en tanto el vecindario de I857 incluye un total de veinticinco abogados. Estos datos en, ALONSO CASTROVIEJO, J.J., «Estructura socioprofesional en Logroño, I75I-I857», en Berceo, núm. II8-II9 (I990), pp. 207-2I7. Por otra parte, la Matrícula del año I842, incluye un total de IO7 abogados en el conjunto de la provincia, en tanto el Censo de Población de I860 -en Archivo Histórico Provincial de La Rioja (en adelante, AHPLR), Sagasta, caja 308-, registra un total de I86 abogados en la provincia, de los que 45 lo están en el Partido judicial de Logroño.

${ }^{6}$ Son pocos los datos de que disponemos para conocer la práctica profesional de los abogados logroñeses con anterioridad a la fundación del Colegio. A tenor del «Inventario de Abogados de los Reales Consejos», que puede consultarse en el Archivo Histórico Nacional (en adelante, AHN), es posible localizar los expedientes personales de cerca de cuatro centenares de abogados procedentes de La Rioja, que solicitaron examinarse como abogados en los siglos XVIII y XIX, pero sólo una pequeña parte de los mismos ejerció la profesión en sus localidades de origen. Ha resultado de gran utilidad para la localización de los expedientes personales de los letrados que formaron parte del Colegio de Abogados de Logroño, el «Inventario de Abogados riojanos: siglos XVIII-XIX», elaborado a partir de aquél por Begoña DE LARRAÑAGA y publicado en Berceo, núm. IO5 (I983), pp. 3I-74. I833.

${ }^{7}$ División territorial de la Península e Islas Adyacentes, aprobada por R.D. de 30 de noviembre de 1833, Madrid,

${ }^{8}$ El reajuste de las Audiencias de Valladolid y de Granada, en las que se suprimen sendas salas de lo civil y lo criminal permite contar con personal suficiente para establecer dos nuevas Audiencias en Burgos y Albacete, asignándose a la primera «las provincias de Burgos, Santander, Logroño, Soria, Álava, Vizcaya y Guipúcoa», Real Decreto de 26 de enero de 1834, uniformando los Tribunales Superiores y mandando observar la nueva distribución del territorio de los mismos con la creación de las Audiencias de Burgos y Albacete, en Colección Legislativa (en adelante, $C L$ ), t. 20, año I834.

9 Decreto de las Cortes, de 20 de julio de 1837, para que los abogados, médicos y demás profesores aprobados puedan ejercer sus profesiones sin necesidad de inscribirse en ninguna corporación ó colegio, en $C L$, t. 23, año I837. Se dispone el restablecimiento del Decreto de 8 de junio de I823 sobre libertad de ejercicio, cuyo tenor literal se insertó en la Gaceta de Madrid, del Jueves, 7 de septiembre de I837. 
Colegios profesionales, en algunos casos centenarios ${ }^{\mathrm{I}}$. Con esta finalidad, el Decreto prevé que se realice un estudio detenido de la mejor manera de armonizar ambos derechos. Entretanto, una Comisión trabaja en el seno del Colegio de Abogados de Madrid con el objeto de reformar y actualizar sus viejos Estatutos de I732. Su trabajo será finalmente aprovechado por la Junta general del Colegio que elevó un proyecto de Estatutos al Ministerio de Gracia y Justicia, regido en este tiempo por el moderado Castro y Orozco, quien no dudó dar a la luz con carácter general, no limitados ya al Colegio de Abogados de la Corte ${ }^{\mathrm{II}}$, los Estatutos para el régimen de los Colegios de Abogados del Reino -mandados guardar por Real Decreto de 5 de mayo de $1838^{12}-$ y cuyos dos primeros artículos disponían:

«Art. I ${ }^{\circ}$.- Los abogados pueden ejercer libremente su profesión con tal que se hallen avecindados y tengan estudio abierto en la población en que residan, sufriendo además las contribuciones que como tales abogados se les impongan. En los pueblos en que exista Colegio, necesitarán también incorporarse en su matrícula.

Art. $2^{\circ}$. Continuarán los Colegios existentes y se establecerán de nuevo, $\mathrm{I}^{\circ}$ en todas las ciudades y villas donde residan los Tribunales supremos y Audiencias del reino; $2^{\circ}$ en todas las capitales de provincia; $3^{\circ}$ en todos los demás pueblos donde hubiere 20 abogados, al menos, de residencia fija; y $4^{\circ}$, en todos los partidos judiciales donde hubiese igual número de 20 abogados, aunque residan en diferentes pueblos de un mismo partido. Los abogados domiciliados en aquellos en donde no se junten en número de 20 , podrán incorporarse en el Colegio más inmediato, ó asociarse los de dos ó mas partidos que se hallen en aquel caso para formar un Colegio, que no podrá componerse de menos de 20 individuos».

De esta manera, Logroño, capital de la provincia de su mismo nombre, debía proceder al establecimiento de un nuevo Colegio de Abogados en el que se integrarían necesariamente todos aquellos letrados que tuviesen estudio abierto en la localidad. Así lo comunicó el Regente de la Audiencia Territorial de Burgos a los abogados logroñeses, procediéndose en los siguientes meses a disponer lo necesario para la instalación del nuevo Colegio ${ }^{\mathrm{I3}}$.

\section{I.I. Establecimiento del Colegio de Abogados de Logroño y primeros pasos}

El 8 de agosto de 1838 se reunieron en una de las salas de la Diputación Provincial de Logroño un total de doce abogados, que, según refleja el acta de la sesión, «componían el

\footnotetext{
Io El primero de los Colegios de Abogados establecidos en España fue el instalado en Barcelona el I4 de abril de 1330. A éste le siguieron, otras corporaciones en otras tantas localidades de la Corona aragonesa: Gerona (I404), Perpiñán (I426) y Zaragoza (I546). En el ámbito de la Corona de Castilla, Valladolid (I592) y Madrid (I595) fueron las primeras en dotarse de sus propias corporaciones de abogados, A partir del siglo XVIII, el número de estos establecimientos se amplía considerablemente con la creación de los Colegios de Sevilla (I706), Granada (I726), Valencia (I759), La Coruña (I76o), Córdoba (I769), Oviedo (I775), Málaga (I776), Palma de Mallorca (I779), Cádiz (I796), Santiago de Compostela (I798), ó Cáceres (I799).

II Sobre la gestación de los Estatutos, PÉREZ-BUSTAMANTE, R., El Ilustre Colegio de Abogados de Madrid, 1596-1996, Madrid, I996, pp. 288-289.

${ }^{12}$ El texto de los Estatutos, en Estatutos para el régimen de los Colegios de Abogados del Reino, con los decretos $Y$ reales órdenes que los aclaran, modifican o derogan; precedidos de una reseña histórica sobre el Colegio de Madrid, su antiguo Monte-Pío y la Sociedad de socorros mutuos de los jurisconsultos; y seguidos de una reseña histórica y de las Constituciones de la Academia Matritense de Jurisprudencia y Legislación, Madrid, publicación de la Revista General de Legislación y Jurisprudencia, I859.

${ }^{\text {I3 }} \mathrm{Al}$ oficio del Regente se refiere el Acta de instalación del Colegio de Abogados de la Capital de la Provincia de Logroño, Archivo del Ilustre Colegio de Abogados de La Rioja (en adelante, ACA), Libro $1^{\circ}$ de Actas de la Junta General, ff. $4 \mathrm{r}-\mathrm{v}^{\circ}$.
} 
mayor número de los abogados estantes en dicha capital» $»^{\top 4}$. La cédula de citación había sido dispuesta por D. Tomás Delgado, quien desempeñó, asimismo, interinamente las funciones de presidente de la nueva Corporación en la sesión de instalación. En calidad de presidente pronunció un breve discurso que versó sobre la nobleza de la profesión de abogado y los deberes de los mismos, argumentando que la nueva situación propiciada por el marco normativo establecido por el real decreto de 5 de mayo de ese año, favorecería sin duda alguna a la profesión, restituyéndola «a su debido esplendor por medio de la vigilancia, emulación y sentimientos delicados que precisamente habían de derivarse de la constitución de los Profesores en Cuerpos Colegiados». Seguidamente, se procedió a la lectura de los Estatutos, instándose a los asistentes a reflexionar acerca de los mismos y formular, en las siguientes reuniones, cuantas observaciones estimasen oportunas. Finalmente, de acuerdo con las previsiones de los Estatutos, se procedió a la elección de los vocales que integrarían la Junta de Gobierno, posponiéndose la decisión acerca de quién debía ocupar el Decanato hasta en tanto se hubiese resuelto la duda acerca de si la mayor antigüedad se refería al título o a la residencia y ejercicio en Logroño.

En sus primeros meses de vida, la nueva corporación desarrolló una intensa actividad, celebrándose en el propio año I838 siete sesiones de la Junta general y, al menos, cuatro de la Junta de Gobierno que se había constituido el mismo día en que había quedado establecido el Colegio. En los años siguientes, ese ritmo se ralentiza, de suerte que la Junta general se reúne, por lo general, una vez al año, en tanto la Junta de Gobierno incrementa moderadamente su actividad.

Las cuestiones que preocupan en este tiempo a la nueva corporación serán precisar cuantos extremos resulten de utilidad para el buen funcionamiento del Colegio, en particular, aclarar a quién corresponde ejercer como primer decano, determinar las funciones del secretario y lo tocante al régimen de las sesiones de sus órganos colegiados, fijar los fondos de la corporación, el modo de proceder en relación a las solicitudes de nuevas incorporaciones al Colegio, o a la hora de designar a los abogados que asumirían la defensa de pobres, así como lo tocante a la contratación de dependientes, la necesidad de una sede estable y el alcance de las funciones que correspondía asumir al Colegio de Abogados de Logroño. Buena parte de ellas se resolvieron tempranamente, en tanto otras se reiteraron una y otra vez en los años siguientes ${ }^{15}$.

Tempranamente el Colegio hubo de enfrentarse a un cambio sustancial en las reglas del juego que habían permitido su creación. Una orden del regente del Reino, de 28 de noviembre de I84I, dirigida a las diferentes Audiencias, declaraba haberse recibido diversas reclamaciones acerca de la contradicción existente entre lo dispuesto en el decreto de in de julio de I837 sobre la libertad de ejercicio de los profesionales de la abogacía y los Estatutos de los Colegios de Abogados posteriormente mandados observar en toda España. A la vista de las mismas, y teniendo en consideración que el mencionado decreto de I 837 había sentado la conveniencia de recabar la información necesaria para armonizar aquel principio con la deseable supervivencia de los Colegios de Abogados, se disponía:

\footnotetext{
${ }^{14}$ Concurrieron a la sesión de instalación del Colegio los Sres. Tomás Delgado, Andrés Velasco, Claudio González del Castillo, Leonardo Viar, Policarpo Atauri, Ángel Lucio García, Celso Planzón, Ezequiel Lorza, Luciano Urtuzar, Manuel Gómez, Rafael Raumel y Salustiano Ruiz, ibídem.

${ }^{15}$ En la sesión de instalación del Consejo se acordó que la Junta de Gobierno recién constituida se ocupase de elaborar un proyecto en el que se contemplasen diferentes aspectos tocantes a la organización y funcionamiento del Colegio, encomendándose al decano que, una vez formado, se llevase a la Junta General para su discusión, ibídem. Sin embargo, las actas de las sesiones de la Junta General y de la Junta de Gobierno no recogen ninguna referencia a la elaboración del mencionado proyecto, en tanto sí se menciona expresamente -en la segunda de las reuniones celebradas por la Junta General- la presentación por parte de D. Tomás Delgado de «un proyecto reglamentario para el establecimiento de una Academia de Jurisprudencia», ACA, Libro $1^{\circ}$ de Actas de la Junta General, ff. $4 v^{\circ}-5$ r.
} 
«... que mientras se reúnen por este Ministerio, en cumplimiento del art. $2^{\circ}$ del decreto de ir de julio, las noticias suficientes para arreglar el régimen de los colegios del modo más favorable a su objeto, y que sea más compatible con la libertad en el ejercicio de la profesión, puedan ejercerla los abogados en todos los puntos de la Monarquía sin necesidad de adscribirse a ninguna corporación o colegio particular $\cdots{ }^{\text {I6 }}$.

La previsión, aunque provisional, fue bien acogida por algunos, valorándose como ventajosa tanto para los abogados como para sus clientes, en la medida en que venía a suponer el refuerzo preciso a los principios de libertad de ejercicio y de amplitud de los medios de defensa en juicio ${ }^{17}$. La principal oposición fue planteada por los propios Colegios de Abogados, que, como en el caso de los de Sevilla, Valladolid, Oviedo, Zaragoza o Murcia, solicitaron que se declarase sin efecto alguno lo previsto en la real orden de 28 de noviembre de $184 \mathrm{I}^{\mathrm{I}}$. Las actas de los órganos de gobierno del Colegio de Abogados de Logroño no permiten conocer la reacción de la corporación riojana ante la nueva situación creada por la disposición mencionada. O sí lo hacen en realidad, toda vez que reflejan una suerte de pausa en la vida colegial, un paréntesis de tres años, que bien podría responder a la situación de interinidad en que habían quedado las corporaciones curiales y que se resolvió, en I844, al disponerse el restablecimiento de los Estatutos de I838 y dotarse de una regulación más precisa a algunos de los extremos contenidos en los mismos, como después se verá.

Con todo, el decreto de 6 de junio de i844 dejaba nuevamente abierta la puerta a una reforma de la abogacía que se entendía necesaria y que se posponía «hasta la publicación de la ley de organización de los tribunales ${ }^{\text {19 }}$. De esta manera, excepción hecha de algunas modificaciones de menor calado o de la que, en I877, alcanzó a los «Estatutos del Colegio de Abogados de Madrid», los trabajos de reforma del estatuto legal de la abogacía y de la organización de las corporaciones se incardinaron en el más amplio proyecto de reforma de las organización de los tribunales. La Ley provisional sobre organización de los Tribunales, de I870, incorporó en su título XXI algunas previsiones acerca de las funciones y organización de los Colegios de Abogados. Posteriormente, se constituyeron una Comisión y una Junta, en I883 y i888, respectivamente, para evaluar las reformas a introducir en la organización de los tribunales. En ambas estuvieron presentes destacados miembros del Colegio de Abogados de Madrid. A esta corporación, se encomendó finalmente también la elaboración de un proyecto de Estatutos para los Colegios de Abogados de España que, tras los pertinentes informes, dio paso a los nuevos Estatutos para el régimen y gobierno de los Colegios de Abogados del territorio de la península, islas Baleares y Canarias, mandados guardar por Real orden de 15 de marzo de $1895^{20}$. Por lo que se refiere a los nuevos Estatutos -cuya vigencia marca el final del período de la vida colegial logroñesa objeto de análisis en estas páginas-, si queda constancia en las actas de la posición del Colegio de Abogados de Logroño. Por un lado, sabemos que se acordó elevar consulta al Ministerio de Gracia y Justicia acerca de la forma en que debía procederse a la renovación parcial de la Junta de Gobierno de conformidad con la regulación dada por los nuevos Estatutos ${ }^{21}$. De otra parte, en la «Reseña de los acontecimientos más importantes

${ }^{16}$ Gaceta de Madrid, Miércoles, I ${ }^{\circ}$ de diciembre de i84I.

${ }^{17}$ En este sentido, ver lo publicado en la Gaceta de Madrid, Miércoles, 6 de diciembre de I84I.

${ }^{18}$ Coincidieron en esa misma valoración la mayor parte de las Audiencias consultadas, que abogaron por el restablecimiento de los Estatutos de 1838 , según señala la exposición de motivos del real decreto de 6 de junio de I844, en Gaceta de Madrid, Sábado I5 de junio de I844. Acerca de la reacción del Colegio de Abogados de Murcia, véase BERMÚDEZ AZNAR, A., Contribución al estudio del corporativismo curial: El Colegio de Abogados de Murcia, Murcia, I969, pp. 65-66. Lo acordado por los abogados zaragozanos, en DEL CAMPO ARMIJO, Luis, El Real e Ilustre Colegio de Abogados de Zaragoza (1546-1952), Zaragoza, I952, pp. 2I-22.

I9 Real decreto de 6 de junio de I844, en Gaceta de Madrid, Sábado, I5 de junio de I844.

${ }^{20}$ Gaceta de Madrid, Sábado, 23 de marzo de I895.

${ }^{21}$ ACA, Libro $2^{\circ}$ de Actas de las sesiones de la Junta de Gobierno, ff. 87-89, sesión de io de mayo de I895. 
que durante el año último han tenido lugar en relación al Colegio», presentada por el Decano en cumplimiento de lo previsto en los nuevos Estatutos, se destacan estos como «el acontecimiento más importante para la Abogacía», declinándose por el Decano una valoración explícita de los mismos:

«No vamos a hacer una relación de las variaciones introducida por los Estatutos en la legislación antigua de la Abogacía, ni a depurar si se ha obrado o no con acierto en cada una de sus indicaciones, porque esto constituiría un trabajo largo, que el Decano que habla -Canuto Sáenz de Tejada-, no ha tenido tiempo de pensar ni de redactar» ${ }^{22}$.

\section{I.2. Estructura y organización del Colegio}

Los Estatutos de i8 88 contemplan la existencia de dos órganos colegiados, la Junta General y la Junta de Gobierno, que cuentan con un decano que las preside y al que corresponde asimismo convocar las sesiones de ambas juntas y fijar el orden del día de las mismas. Junto al decano, forman parte de la Junta de Gobierno dos diputados, un tesorero y un contador-secretario, cuyas funciones aparecen fijadas en los propios Estatutos.

\section{I.2.I. La Junta General del Colegio de Abogados de Logroño}

Los Estatutos de I838 dedican dos preceptos -artículos if y I2- a regular la estructura, régimen de sus sesiones y competencias de las Juntas Generales de los Colegios de Abogados. De acuerdo con el primero de ellos, cada Colegio debía celebrar una Junta General anual en el mes de diciembre, a la que serían convocados todos los individuos que formasen parte del mismo. La citación, así como la determinación de la fecha en que debían reunirse corresponderían al decano, incluyéndose necesariamente en el orden del día de la Junta -según se prevé en el artículo I2- los siguientes extremos : aprobación de las cuentas presentadas por la Junta de Gobierno correspondientes al último ejercicio, aprobación del presupuesto de gastos para el ejercicio siguiente, aprobación de las medidas disciplinarias propuestas por la Junta de Gobierno y nombramiento de los miembros de esta última para el año siguiente. Por lo que se refiere al régimen para la adopción de acuerdos, se prevé artículo II- que deberán conformarse «por la mitad mas uno de los concurrentes».

Las previsiones contenidas en los Estatutos fueron puntualmente modificadas en el período aquí analizado. Por lo que se refiere a la composición de las Junta Generales, una Real orden de 3I de julio de I850, introdujo el criterio del ejercicio o no de la profesión por parte de los colegiados a la hora de establecer, no su pertenencia a la Junta General, que resultaba incuestionable desde el momento mismo de la incorporación al Colegio, pero sí su derecho a participar anualmente en la elección de los miembros de la Junta de Gobierno. Esta restricción, que afectaba a los derechos de «los abogados incorporados que no tengan estudio abierto ni sufran cargas en el Colegio», tuvo su origen en una consulta formulada por el Colegio de Abogados de Córdoba y, posteriormente, también como respuesta a una consulta, planteada en este caso por el Colegio de Abogados de Valencia, una nueva disposición, de 26 de febrero de 1853 , vino a precisar que la exclusión de las votaciones para la elección de los individuos de la Junta de Gobierno no alcanzaría a aquellos colegiados que, aún no ejerciendo la profesión de manera regular con estudio abierto en la localidad, cumpliesen los deberes que el Colegio les impusiese, aceptando comisiones o encargos y satisfaciendo puntualmente las cuotas ordinarias o extraordinarias para el sostenimiento de la corporación, toda vez que se entendía que las cuotas que se abonaban para los gastos del Colegio debían considerarse entre «las cargas del Colegio» ${ }^{23}$. La cuestión se resolverá en los nuevos Estatutos aprobados en 1895 ratificándose el derecho a voto de todos los colegiados

\footnotetext{
${ }^{22}$ Ibídem, Libro $2^{\circ}$ de Actas de las sesiones de la Junta General, ff. 29-58, sesión de 31 de enero de I896.

${ }^{23}$ Las dos reales órdenes en $C L$, tt. 50, año I850, p. 672 y 53, año I853, pp. 2I7-2I8.
} 
que figurasen inscritos en la matrícula oficial del respectivo Colegio y excluyéndose, sin embargo, del ejercicio del voto pasivo a los colegiados no ejercientes ${ }^{24}$.

También fue objeto de alguna modificación el régimen de sesiones de las Juntas Generales. Así, la convocatoria de las Juntas Generales, que los Estatutos asignaban al decano, pasó a depender de las Juntas de Gobierno tal como después se recogerá en los nuevos Estatutos vigentes desde I895, que atribuyen a esta última la presidencia de esa reunión ordinaria anual ${ }^{25}$. Por otra parte, si inicialmente los Estatutos habían precisado que debía celebrarse una Junta anual ordinaria en el mes de diciembre, en I868, sendas disposiciones de abril y diciembre, adelantaron a los meses de junio y mayo, respectivamente, la celebración de las reuniones ordinarias anuales de las Juntas de gobierno de los Colegios de Abogados, con la vista puesta en armonizar el nombramiento de los denominados «abogados de pobres» y el repartimiento de la contribución industrial correspondiente al ejercicio económico ${ }^{26}$. Los Estatutos de 1895 señalarán finalmente el mes de enero de cada año para la celebración de las Juntas Generales ordinarias ${ }^{27}$.

Por lo que se refiere a la adopción de acuerdos, los Estatutos de i838 establecían artículo II-, como regla general, la mayoría absoluta. El real decreto de 3 de abril de I868, antes mencionado, precisó, por lo que se refiere a la elección de los miembros de la Junta de Gobierno, que sería «necesaria la mayoría absoluta de los votos de los concurrentes para formar acuerdo, y decidiendo el Decano en caso de empate» ${ }^{28}$.

Entre I838 y i895 la Junta General del Colegio de Abogados de Logroño celebró cerca de un centenar de reuniones. A las sesiones ordinarias anuales celebradas puntualmente en el mes de diciembre -en junio desde i868- se sumaron otras convocadas por el decano para tratar diferentes asuntos de interés general del Colegio y sesiones extraordinarias convocadas a instancia de la Junta de Gobierno, como la convocada para el 30 de enero de I894, en que se dieron cita para celebrar Junta General extraordinaria «acordada por la Junta de Gobierno de este Ilustre Colegio, en sesión de 27 del actual», pero no pudo celebrarse por falta de quorum ${ }^{29}$. El motivo de la convocatoria no era otro que la difícil situación económica por la que atravesaba el Colegio, lo que llevó a la Junta de Gobierno a decidir la convocatoria extraordinaria de una Junta General en la que se trataría acerca del incremento de la cuota de ingreso, de la solicitud de autorización al Ministerio para la creación de un nuevo sello para el bastanteo de poderes, o la adopción de «todos los recursos y repartos que se crean necesarios para normalizar la situación económica del Colegio» ${ }^{30}$.

${ }^{24}$ Estatutos para el régimen de los Colegios de Abogados del territorio de la Península, cit., arts. 50 y $5 \mathrm{I}$.

${ }^{25}$ Por lo que se refiere a la citación de los miembros de las Juntas Generales, los Estatutos de I895 disponen que se efectuarán por medio de papeletas impresas rubricadas por el secretario del Colegio y repartidas a domicilio durante la segunda quincena del mes de diciembre de cada año, ibídem, art. 68.

${ }^{26} \mathrm{El}$ art. II de los Estatutos fue modificado inicialmente por un real decreto de 3 de abril, a tenor del cual los Colegios debían celebrar Junta general ordinaria el primer domingo del mes de junio. En la práctica, sin embargo, no se consiguió armonizar la renovación de los cargos de la Junta de Gobierno, la designación de los abogados de pobres y el posterior repartimiento, con la debida exclusión de los nombrados para la defensa de pobres, de la contribución industrial, toda vez que se disponía de muy corto espacio de tiempo desde la renovación de la Junta de Gobierno. De este modo, un decreto de I5 de diciembre de I868 fijó el mes de mayo dejando en manos del decano la precisión del día en concreto- para la reunión ordinaria que debían celebrar anualmente las Juntas generales de los Colegios de Abogados, CL, t. 6o, año I868, pp. 378-379 y 937-938.

${ }^{27}$ Estatutos para el régimen de los Colegios de Abogados del territorio de la Península, cit., arts. 64 y 65.

${ }^{28}$ Previamente, una real orden de 26 de enero de I 840 había aclarado, a consulta de la Junta de Gobierno del Colegio de Abogados de Granada, que siendo el nombramiento de los individuos de las Juntas de Gobierno uno de los acuerdos más importantes que adoptaban las Juntas generales, no podía caber duda acerca de que el nombramiento «se verifique a pluralidad absoluta de votos», $C L, \mathrm{t}, 32$, añoı 840 .

${ }^{29}$ ACA, Libro $2^{\circ}$ de Actas de las sesiones de la Junta General, f. 3.

${ }^{30}$ Ibídem, Libro $1^{\circ}$ de Actas de las sesiones de la Junta General, s.f., acta núm. 93, Junta de Gobierno. 
Por las actas de las diferentes sesiones, que, con contadas excepciones, fueron transcritas en el correspondiente libro, conocemos el pormenor de lo tratado en las mismas. Por lo que se refiere a cómo debían formalizarse las actas, eran recogidas en el correspondiente Libro y suscritas por el decano y el secretario, expresándose en las mismas la fecha y hora de celebración de la sesión, el lugar en que tiene lugar la reunión, los asistentes, la referencia a la lectura, en su caso, y aprobación del acta o las actas de las sesiones anteriores, la relación de asistentes y los asuntos tratados y acuerdos adoptados, en su caso. En los primeros años, las actas de la Junta General de la corporación logroñesa son muy escuetas, en tanto a partir de I885 responden ya a una misma estructura más ordenada y completa, relacionándose en las mismas de forma numerada las diferentes cuestiones tratadas, con expresión de los acuerdos adoptados.

La cuestión del número de asistentes preocupó a la Junta general en algunas ocasiones en las que, habiéndose convocado la sesión con las debidas formalidades y no congregándose el suficiente número de abogados para poder adoptar válidamente un acuerdo sobre los asuntos a tratar en la misma, fue precisa una nueva convocatoria en los días siguientes.

Quiénes debían ser convocados a las reuniones resultaba claro a la luz de los Estatutos. Como antes se vio, todos los matriculados en el Colegio formaban parte de su Junta General. De esta forma, las actas recogen, sesión tras sesión, la indicación de que se ha procedido a la citación con la necesaria antelación «de todos los incorporados al Colegio», o «de los individuos que componen el Colegio». Llama la atención en este sentido la expresión utilizada en las actas de las sesiones celebradas en I884, en las que se indica que «se reunieron los Sres. Colegiales que al margen se expresan -nueve en total, incluyendo al decano y al secretario- previa convocatoria hecha en forma con la necesaria antelación a todos los abogados incorporados al Colegio de esta capital que tuvieran estudio abierto», o, utilizando una fórmula muy similar, «a todos los Sres. Abogados incorporados a este Ilustre Colegio que se hallasen en el ejercicio de la profesión» ${ }^{3 \mathrm{I}}$.

Mayor interés suscitó, sin duda, determinar si los acuerdos adoptados por la mayoría de los presentes obligarían o no a los que no hubiesen concurrido a la sesión. En la celebrada el 20 de septiembre de 1838 , tras haberse discutido acerca de la naturaleza del Colegio de Abogados y convenido en que en ese tipo de corporaciones «lo acordado por el mayor número de sus vocales tiene fuerza obligatoria para todos los restantes», se resolvió que, al objeto de que todos ellos estuviesen informados de los acuerdos, «el acta que se levantase, extendida y formalizada en pliego suelto, además de la que se insertase en el libro, se circulase a todos los Sres. Colegiales para que la firmasen y se enterasen de su contenido» ${ }^{32}$. De nuevo en 1849 se plantearon si los asistentes componían número suficiente para proceder, como se pretendía, a la reelección de los miembros de la Junta de Gobierno saliente y si debía entenderse que los que no habían concurrido aprobaban también la decisión que se adoptase por los presentes en la reunión, resolviéndose que no había inconveniente en ello y aduciéndose además que algunos de los ausentes habían manifestado previamente su respaldo a la reelección que se pretendía.

\section{I.2.2. La Junta de Gobierno del Colegio de Abogados de Logroño}

La Junta de Gobierno del Colegio de Abogados de Logroño se constituyó el 8 de agosto de I 838 con dos diputados, un tesorero y un contador-secretario, tal como establecía el art. I3 de los Estatutos de I838, dejándose pendiente, hasta su resolución por la propia Junta, determinar a quién correspondía ejercer la presidencia de la Junta en su calidad de

\footnotetext{
${ }^{31}$ Ibídem, s.f., actas de las sesiones de $\mathrm{I}^{\mathrm{O}}$ y 5 de junio de I 884 .

${ }^{32}$ Ibídem, ff. $5 v^{\circ}-6$ r.
} 
decano del Colegio logroñés ${ }^{33}$. Apenas una semana más tarde, volvía a reunirse la Junta, abordándose dos asuntos: el error cometido en la convocatoria para la sesión de constitución, al haberse citado a D. Andrés Velasco, quien asistió y tomó parte en la instalación del Colegio, habiéndosele citado al hallarse circunstancialmente en la capital, pero resultando conocido que era vecino y tenía domicilio en Navarrete. Analizada la situación y constatado el error, se convino en que no debía convocársele de nuevo a las sesiones de la Junta general. En segundo lugar, se estudió la reclamación planteada por D. José Ordoyo, quien manifestaba ser más antiguo como abogado en Logroño que D. Tomás Delgado. Se acordó estimarla y, dado que Ordoyo había sido elegido diputado $\mathrm{I}^{\circ}$ de la Junta de Gobierno, ponerlo en conocimiento de la Junta General para que adoptasen las medidas tendentes a reemplazarle ${ }^{34}$.

De conformidad con lo previsto en el art. I4 de los Estatutos, la Junta debía renovarse en su totalidad cada año, procediéndose por la Junta General a la elección de entre los colegiales que reuniesen ciertos requisitos: llevar seis años en el Colegio y no haber sido objeto de amonestación, según lo previsto en el art. I3 de los Estatutos de I838. La antigüedad en el Colegio se elevó posteriormente a diez años para los decanos y se redujo a cinco para los demás cargos por el ya citado real decreto de 6 de junio de I844, retornándose una década después a los requisitos establecidos en los Estatutos ${ }^{35} \mathrm{y}$ manteniéndose inalterados hasta la reforma estatutaria de I895, en la que se dispusieron diferentes requisitos en atención al Colegio de que se tratase, señalándose, en el caso de la corporación logroñesa, diez años de antigüedad en el Colegio y el mismo período de ejercicio profesional para ser elegido decano y ocho años de antigüedad y ejercicio para ser elegido vocal -término con el que la ley designa en ese tiempo a los anteriores diputados-, tesorero o secretario.

Por lo que se refiere al modo en que debía procederse a la elección de la Junta de Gobierno, los Estatutos de I838 se limitaban a señalar, en su art. I2, que era competencia de la Junta General y que «se haría a pluralidad de votos». Los libros de actas del Colegio logroñés reflejan, desde I885, el número de votos recibidos por cada uno de los individuos $y$, hacia el final del período estudiado, permiten conocer la adopción del nuevo sistema electoral implantado en I882 en el Colegio de Abogados de Madrid, por el que se introducía la novedad de que la votación tuviese lugar ante la mesa electoral presidida por la Junta de Gobierno y constituida al efecto en el día y lugar señalados ${ }^{36}$. De conformidad con esas previsiones y con lo dispuesto en la real orden de I7 de abril de I89o, asimismo citada por el decano, la Junta de Gobierno del Colegio de Abogados de Logroño acordó, en I894:

«... que a las doce la mañana del día tres de junio próximo tenga lugar en el Salón de esta Corporación la elección de los vocales que han de formar esta Junta de Gobierno durante el inmediato año económico, cerrándose la votación a la una de la tarde del indicado día para cuyo objeto se repartirán a los Colegiados en ejercicio las oportunas candidaturas impresas y selladas con el de este Colegio, citándoles en forma el Decano por medio de la correspondiente convocatoria e interesándoles para que asistan y tomen parte en la referida elección emitiendo su voto a favor de los candidatos que reúnan las

\footnotetext{
${ }_{33}$ Ibídem, ff. $4 \mathrm{r}-\mathrm{v}^{\mathrm{o}}$, Acta de instalación del Colegio de Abogados de la capital de la Provincia de Logroño.

${ }^{34}$ Ibídem, Libro $1^{\circ}$ de Actas de la Junta de Gobierno, f. Ir, acta de la sesión de 14 de agosto de 1838 .

${ }_{35}$ Gaceta de Madrid, Sábado, I5 de junio de I844. Por real decreto de I de abril de I855 se derogó lo previsto en el art. 6r del real decreto citado acerca de los requisitos para ser miembro de las Juntas de Gobierno de los Colegios de Abogados.

${ }^{36}$ Real orden de 25 de febrero de 1882 , refundiendo y adicionando la de 3 de mayo de 1877 referente, entre otros extremos, a la provisión de cargos de la Junta de Gobierno del Colegio de Abogados de esta Corte, CL, t. 74, año I882.
} 
condiciones legales con cuyo objeto y demás procedente se constituirá el Colegio en Junta general según el artículo I2 del Real Decreto de 28 de Mayo de I $838 »^{37}$.

Efectuada la elección, tenía lugar, en la misma o en la siguiente sesión, la toma de posesión formal de los nuevos cargos, comenzando a ejercer sus funciones desde ese día. Con frecuencia las actas reflejan el agradecimiento sincero a los miembros de una determinada Junta por la meritoria labor realizada ${ }^{38}$.

Los cargos de la Junta de Gobierno eran, según el art. I4 de los Estatutos, irrenunciables, salvo en el supuesto de reelección. La Junta General del Colegio de Abogados de Logroño se enfrentó a este problema inmediatamente después de iniciada su andadura. En la sesión celebrada el 22 de agosto de 1838 tuvo que resolver el incidente planteado por el secretario, quien manifestó su voluntad de renunciar a la Secretaría al tener que ausentarse de Logroño. La decisión adoptada, acorde con los Estatutos, pasó por la designación de un secretario-adjunto que asistió a la Junta durante la ausencia del secretario $^{39}$. No fue ésta la única ocasión en la que se registró la ausencia del secretario, resolviéndose entonces con el nombramiento de otro de los individuos de la Junta como secretario accidental. Un mayor problema se planteó al producirse el fallecimiento de alguno de los miembros de la Junta, procediéndose en este caso a la renovación parcial de la Junta de Gobierno.

En el período analizado, la Junta de Gobierno del Colegio riojano experimentó otros cambios en su estructura. El referido real decreto de 6 de junio de i844 redujo el número de los miembros de las Juntas de Gobierno, fijándolo en atención al número de abogados inscritos en el mismo, lo que para nuestro Colegio suponía la pérdida de uno de sus diputados en el año I849. El acta de la sesión de la Junta General celebrada el 30 de diciembre de 1848 , en la que debía procederse a la elección de los miembros de la Junta de Gobierno para el año siguiente, indica que por parte del decano se informó de que, al no llegar a treinta el número de individuos que formaban el Colegio, debía reducirse la Junta a tres individuos: el decano, un diputado y un secretario-contador ${ }^{40}$, manteniéndose este único diputado hasta la elección realizada el 5 de junio de I870, a partir de la cual fueron elegidos nuevamente dos diputados, no alterándose tampoco este número con la entrada en vigor de la reforma estatutaria en $1895^{4 \mathrm{I}}$.

La presidencia de la Junta de Gobierno correspondía al decano -art. i6 de los Estatutos de I838-, quien decidía asimismo su convocatoria. La Junta debía reunirse, según lo previsto en los Estatutos, «un mínimo de dos veces al mes», extremo éste que no se cumplió en el caso de la Junta de Gobierno del Colegio de Logroño sino en contadas ocasiones. Para el período estudiado, se conservan las actas de más de noventa reuniones ${ }^{42}$, pero su frecuencia no fue en absoluto regular, reuniéndose casi siempre dos o tres veces al año, e incumpliendo en todo caso el mandato estatutario incluso en los años I893 y I894, en los que los libros de actas reflejan una mayor actividad, con siete y diecisiete reuniones, respectivamente.

Al igual que la Junta General, también la Junta de Gobierno padeció en algún momento la falta de asistencia de sus miembros, lo que hizo necesarias nuevas

\footnotetext{
${ }^{37}$ ACA, Libro $2^{\circ}$ de Actas de la Junta de Gobierno, sesión de I4 de mayo de I894.

$3^{8}$ Ver, v.g., la toma de posesión en el año I893, presidida por el decano saliente, en ibídem, Libro $1^{\circ}$ de Actas de la Junta General, s.f., acta núm. 85, sesión de 3 de julio.

39 Ibídem, f. $5 \mathrm{v}^{\circ}$.

$4^{\circ}$ Libro $^{\circ}$ de Actas de la Junta General, ff. IIr y vo.

${ }^{41}$ Ibídem, f. 2I5r, «Copia de la Comunicación del Sr. Decano D. Tomás Delgado al Sr. D. Tadeo Salvador».

${ }^{42}$ El Libro $1^{\circ}$ de Actas de la Junta de Gobierno, en ACA, recoge de forma consecutiva y sin intercalar diligencia alguna que explique el lapso temporal, las sesiones celebradas el 28 de octubre de I838 y el i5 de marzo de i 850 .
} 
convocatorias por no contar con el quórum necesario. Resulta especialmente llamativa esa ausencia cuando en 1894 fue preciso convocar hasta en tres ocasiones a fin de concluir la toma de posesión formal de los nuevos miembros de la Junta de Gobierno ${ }^{43}$.

\section{I.2.3. Los primeros decanos}

El Decanato del Colegio de Abogados de Logroño fue desempeñado durante el período aquí estudiado por un total de trece abogados ${ }^{44}$. De entre ellos destaca la labor desempeñada por los dos primeros -D. Tomás Delgado y D. José Ordoyo- en el Decanato del Colegio, en el que se turnaron desde el establecimiento de la corporación por espacio de treinta años.

El primero de los trece, Tomás Delgado, abogado en ejercicio en la ciudad de Logroño desde $1822^{45}$, ejerció como decano hasta en tres momentos. La primera vez, con carácter provisional, en la sesión de instalación del Colegio, siendo él quien se ocupó de la convocatoria de los abogados residentes en Logroño a la sesión celebrada el 8 de agosto de I838. La segunda, en $1845^{46}$, hasta que, cuatro años más tarde, tras haber sido reelegido en varias ocasiones, anunció que deseaba que también el resto de sus compañeros pudiesen tener el gran honor de ejercer como decanos ${ }^{47}$. Con todo, apenas tres años después, comenzó el tercer período de Decanato de Tomás Delgado, extendiéndose en esta ocasión por espacio de quince años consecutivos, hasta que su designación como magistrado de la Audiencia de Albacete, en I867, le obligó a abandonar definitivamente el cargo de decano ${ }^{48}$.

Delgado había sido miembro electo de la Junta Provisional de Gobierno de la ciudad de Logroño el I I de julio de i843 en apoyo del programa radical del Ministerio López, desempeñando también el encargo de la Secretaría de la Diputación Provincial de Logroño y la ya mencionada magistratura de la Audiencia de Albacete ${ }^{49}$. Además, en virtud de la Real orden de i4 de diciembre de I848, mereció personalmente los honores de magistrado de la Audiencia Territorial de Burgos tras haber sido reelegido en tres ocasiones como decano del Colegio de Abogados de Logroño ${ }^{50}$. Tomás Delgado fue uno de los abogados más prestigiosos de Logroño y trató de abrirse paso, aunque sin éxito, en la vida política, presentando su candidatura a Cortes en el denominado Bienio Progresista ${ }^{5 \mathrm{I}}$.

José Ordoyo era el más antiguo de los abogados en ejercicio en la ciudad de Logroño en el momento de la creación del Colegio, asumiendo como tal el Decanato en la

${ }^{43}$ ACA, Libro $2^{\circ}$ de Actas de la Junta de Gobierno, actas de las sesiones de 27 de junio (f. 35 ), de I $^{\circ}$ de julio (f. 37), de 7 de julio (ff. 4I-42) y de I4 de julio de I894 (ff. 43-44). Además, la siguiente sesión, celebrada el 24 de julio tuvo que suspenderse también por falta de quórum (f. 45).

${ }^{44}$ Los Sres. Tomás Delgado, José de Ordoyo, Tadeo Salvador, Celso Planzón, Juan Manuel de Miguel, Miguel Salvador, Ildefonso Sicilia, Julio Farias, Rafael P. Gil, Zacarías Ayala, G. Somalo Martínez, Eladio Ramos y Canuto Sáenz de Tejada.

${ }^{45}$ ACA, Libro $1^{\circ}$ de Actas de la Junta de Gobierno, f. Ir, acta de la sesión de I4 de agosto de I838. El expediente personal de D. Tomás Delgado puede verse en AHN, Consejos, leg. I2IO3, exp. 3.

${ }^{4}$ Ibídem, Libro $1^{\circ}$ de Actas de la Junta general, ff. 9r y v ${ }^{\circ}$, acta de la sesión de I5 de diciembre de I844.

47 Ibídem, ff. IIr y v ${ }^{\circ}$, acta de la sesión de 30 de diciembre de I848.

${ }^{48}$ Así lo comunicó el io de agosto de i867 a D.Tadeo Salvador, diputado único de la Junta de Gobierno del Colegio de Abogados, a quien correspondió asumir interinamente el Decanato, ibídem, f. 2Ir, «Copia de la comunicación del Sr. Decano D. Tomás Delgado al Sr. D. Tadeo Salvador».

49 BERMEJO MARTÍN, F. y DELGADO IDARRETA, J.M., La Administración Provincial Española. La Diputación Provincial de La Rioja, Logroño, I989, p. 83.

${ }^{\circ} \mathrm{CL}$, t. 40, año I848, pp. 4II-4I2.

${ }^{51}$ OLLERO VALLÉS, J.L. (dir.), Diccionario biográfico de los parlamentarios de La Rioja (1833-2008), Logroño, Instituto de Estudios Riojanos, 20IO, pp. 9I-92, voz «Justo Tomás Delgado». Justo Tomás Delgado, hijo de Tomás Delgado, nació en Logroño en I835. 
sesión de I8 de agosto de I838 y permaneciendo al frente del mismo hasta finales de I844, en que se admitió la renuncia que presentó de su cargo en atención a su avanzada edad y a los achaques que padecía, agradeciéndole sentidamente el celo con que se había distinguido en su labor como decano «por sostener el lustre de la Corporación y de la profesión» ${ }^{2}$. No obstante, cuatro años más tarde, se produjo un nuevo turno con Delgado. Tras anunciar éste que no aceptaría un nuevo mandato y abogar porque se diese la oportunidad de desempeñar tan alto honor a otros colegiados, curiosamente el elegido por unanimidad resultó ser el otro de los miembros de la Corporación que hasta el momento había ejercido como decano. El segundo de los períodos de Decanato de Ordoyo se extendió hasta finales de I852 en que, de nuevo, dio paso a Tomás Delgado.

José Ordoyo fue Diputado provincial por Alfaro y, al igual que Delgado, formó parte de la Junta Provisional de Gobierno de la provincia de Logroño establecida el 6 de septiembre de I840, asumiendo la Presidencia de la misma ${ }^{53}$.

La primera de las etapas de Decanato de Ordoyo estuvo marcada, que duda cabe, por la necesidad de resolver los problemas iniciales que trajo consigo la puesta en marcha del Colegio. Los más relevantes y que tenían que ver con la inscripción de nuevos colegiales, llegaron a enfrentar al Colegio con el alcalde-constitucional y juez de primera instancia de Logroño, D. Diego Ponce de León, al considerarse por parte del decano que «miraba las prerrogativas y decoro del Colegio con desprecio» ${ }^{54}$. Fue preciso asimismo organizar la Abogacía de pobres, determinando el modo en que se llevaría a cabo anualmente la comisión a dos de los colegiales y aclarando qué hacer en caso de incompatibilidad o si hubiese necesidad de más abogados de pobres al haberse incrementado el número de causas criminales ${ }^{55}$. Además estuvo presente el sempiterno problema de la falta de un local adecuado y fue preciso ocuparse de la dotación de los primeros medios materiales a disposición del Colegio ${ }^{56}$. En la segunda etapa al frente del Decanato, la actuación más relevante del Colegio tuvo que ver con la creación de una Comisión -encargada de elaborar el informe sobre el proyecto de Código Penal que se había solicitado al Colegio por parte del Juzgado de primera instancia de Logroño a resultas de la real orden expedida al efecto por el Ministerio de Gracia y Justicia- para la que fueron designados, por acuerdo unánime, D.Tomás Delgado, D. Salustiano Ruiz, D. José Apellániz y el secretario del Colegio, D. Tadeo Salvador ${ }^{57}$.

Este último será el tercero de los decanos del Colegio logroñés, resultando asimismo reelegido en varias ocasiones desde el año 1869 en que hubo de hacerse cargo provisionalmente del Decanato por el cese de Delgado, hasta que, tras un nuevo período al frente del Decanato -desde junio de i878- finalmente hubo de dejar el cargo de decano para asumir un destacado puesto en el Gobierno de la Provincia ${ }^{58}$. Como los anteriores, D. Tadeo Salvador Sáenz formó parte de la Junta Provisional de Gobierno de la ciudad de Logroño establecida el $\mathrm{I}^{\circ}$ de julio de $\mathrm{I} 843$, ejerciendo ese tiempo el empleo de alcalde

${ }^{2}$ ACA, Libro $1^{\circ}$ de Actas de la Junta general, ff. 9r- ${ }^{\circ}$, acta de la sesión de I5 de diciembre de I844.

53 BERMEJO MARTÍN, F. y DELGADO IDARRETA, J.M., La Administración Provincial Española, cit. , p. 80.

${ }^{54} \mathrm{ACA}$, Libro $1^{\circ}$ de Actas de la Junta general, ff. $5 \mathrm{v}^{\circ}-6 \mathrm{v}^{\mathrm{o}}$, acta de la sesión de 20 de septiembre de I838.

${ }_{55}$ Ibídem, ff. $6 v^{\circ}-8 \mathrm{r}$ y IIr y v ${ }^{\circ}$, actas de las sesiones de I7 de octubre y 22 de diciembre de 1838 y de la de 30 de diciembre de 1848 .

${ }^{56}$ En la sesión de la Junta general celebrada el 22 de agosto de 1838 se acordó la adquisición de material de oficina y la distribución de los gastos entre todos los miembros del Colegio, ibídem, f. $5 \mathrm{v}^{\circ}$.

57 Ibídem, ff. I3r y v , acta de la sesión de 23 de mayo de I85I.

$5^{8}$ En la Junta general de I de junio de I873 es relevado como decano y designado como vocal de la Junta de Gobierno para ocupar la plaza que quedaba vacante por la salida de Celso Planzón que había sido elegido como nuevo decano, ibídem, ff. $23 \mathrm{~V}^{\circ}-24 \mathrm{r}$, acta de la sesión de $\mathrm{I}^{\mathrm{O}}$ de junio de $\mathrm{I} 873$. Ver también las de 2 de junio de $\mathrm{I} 878$ (ff. $27 \mathrm{r}-\mathrm{v}^{\circ}$ ), en la que actúa como presidente interino y 3 de septiembre de i882 ( s.f., acta núm. 48). 
segundo de la capital riojana ${ }^{59}$. En su Decanato el Colegio elaboró un Informe sobre la reforma de los aranceles notariales ${ }^{60}$ y hubo de ajustar a las nuevas previsiones legales la matrícula del subsidio industrial y las exenciones previstas para la misma y las cuotas de ingreso y colegial, que se vieron reducidas en este período y sobre las que se establecieron asimismo algunas exenciones. En cuanto al problema de la falta de local propio, el Colegio encontró acomodo en este tiempo, ocasionalmente, en la nueva sede de la corporación municipal, en los salones correspondientes al Juzgado municipal, aún cuando continuaron reuniéndose también en el domicilio de alguno de los miembros de la Junta de Gobierno. El final de su mandato coincidió con el tiempo en que se produjo la instalación de la nueva Audiencia de lo Criminal en Logroño a cuya recepción acudieron los miembros de la Comisión designada al efecto por la Junta General en la sesión de 3I de diciembre de $1882^{61}$.

Posteriormente, ocuparon el Decanato los señores Juan Manuel de Miguel y Guarro (1882-1885) ${ }^{62}$, Miguel Salvador Sáenz y Sáenz-Rodrigáñez (I885-I886) ${ }^{63}$, Ildefonso Sicilia (I886) ${ }^{64}$, Julio Farias Merino (I886-I888) ${ }^{65}$, Franco Iriarte Echarri (I888-I889) ${ }^{66}$, Rafael Pedro Gil Marquina (I889-I890) ${ }^{67}$, Zacarías Ayala Gil (I890-I89I) ${ }^{68}$, Guillermo

59 BERMEJO MARTÍN, F. y DELGADO IDARRETA, J.M., La Administración Provincial Española, cit. , p. 83.

${ }^{60}$ En la sesión de la Junta General de 30 de junio de I 878 el decano informó acerca del oficio recibido del Presidente de la Audiencia Territorial de Burgos y en la celebrada el ig de julio del mismo año «se dio lectura por mi el Secretario de la contestación que se daba a la comunicación del Excmo. Sr. Presidente de la Audiencia de Burgos sobre la reforma de los Aranceles notariales, la cual fue aprobada y remitida a su destino cumpliendo de este modo lo acordado en la Junta anterior», ACA, Libro $1^{\circ}$ de Actas de la Junta General, ff. $27 \mathrm{v}^{\circ}-28 \mathrm{v}^{\circ}$.

${ }^{6 r}$ D. Tadeo Salvador Sáenz había presentado su renuncia cuatro meses antes, trasladando al conjunto de la Corporación «el testimonio más vivo de afecto a sus compañeros, al propio tiempo que el sentimiento de que se hallaba poseído al verse imposibilitado de compartir con los Sres. Colegiados las honrosas ocupaciones profesionales en razón a las innumerables e incompatibles atenciones del elevado cargo con que la confianza del Gobierno de S.M. le ha honrado en esta Provincia», ibídem, s.f., acta núm. 48, sesión de 3 de septiembre de I882.

${ }^{62}$ Doctor en leyes, ingresó en el Colegio en el año I857. En I87i fue nombrado secretario de la Junta de Gobierno, siendo relevado en I873. Cinco años después ejerció como vocal I ${ }^{\circ}$ de la Junta y el 3 de septiembre de I882 actuó como decano accidental, resultando elegido como decano en esa misma sesión. Relevado en I885, volvió a asumir el cargo de diputado I ${ }^{\circ}$ de la Junta por espacio de dos años. Falleció el I7 de septiembre de I886. Fue comendador de número de la Orden de Isabel la Católica, magistrado suplente de la Audiencia de lo Criminal de Logroño y presidió la Comisión Permanente de la Diputación Provincial.

${ }^{6}$ Ingresó en el Colegio el 25 de junio de i87i. Ejerció como secretario y vocal $2^{\circ}$ de la Junta de Gobierno, cargo este último al que retornó tras su paso por el Decanato. En el año I893 residió durante algún tiempo en Madrid, lo que determinó su elección como uno de los tres representantes del Colegio de Abogados de Logroño en la reunión de la Junta Magna o Consejo Jurídico que debía reunirse en la Real Academia de Jurisprudencia y Legislación. En I894 formó parte de la Comisión encargada de elaborar el informe solicitado por el Ministerio de Gracia y Justicia en relación a los proyectos de reforma de Ley del Poder Judicial y de Ley de Enjuiciamiento Civil.

${ }^{64}$ Licenciado en derecho civil y canónico por la Universidad de Barcelona en I874, ingresó en el Colegio el 20 de enero de I875. En I882 accede como diputado $2^{\circ}$ a la Junta de Gobierno y en I886 es elegido decano, retornando a ejercer como diputado $2^{\circ}$ y posteriormente como tesorero. En I895 solicitó su baja en el Colegio en atención a su delicada salud.

${ }^{6}$ Licenciado en I878 por la Universidad de Madrid, se incorporó al Colegio el Io de marzo de I879, teniendo su bufete abierto en la calle de la Villanueva de la capital riojana. Ese mismo año pasó a desempeñar el cargo de secretario de la Junta de Gobierno. Entre i 887 y i 888 ejerció como decano y posteriormente, en I889, pasó a ser diputado segundo. Entre I890 y I895 desempeñó el cargo de tesorero del Colegio de Abogados logroñés.

${ }^{66}$ Licenciado en derecho por la Universidad de Valencia, se expidió su título en Madrid el 30 de noviembre de I880. En enero de i88I se incorporó al Colegio de Logroño y le correspondió el ejercicio de la Secretaría de la Junta. En I884 fue elegido tesorero, cinco años más tarde diputado $\mathrm{I}^{\circ}$ y posteriormente diputado $2^{\circ}$ en varias ocasiones hasta su elección como decano en I888. Su bufete estaba ubicado en la calle Sagasta de Logroño.

${ }^{67}$ Licenciado en derecho por la Universidad de Valladolid, con título expedido en Madrid, el 24 de noviembre de I882. Ingresó en el Colegio el 26 e diciembre de ese mismo año y en la sesión de la Junta general celebrada el 26 de mayo de i 889 fue designado decano. Relevado en el año siguiente, formó parte de la Junta de Gobierno como diputado I ${ }^{\circ}$. En I893 se postuló para formar parte de la Comisión de tres representantes del Colegio de Abogados de Logroño que acudiría a la Junta Magna o Consejo Jurídico antes mencionada. 
Gonzalo Martínez (I89I-I892) ${ }^{69}$, Eladio Ramos Luelmo (I892-I893) ${ }^{70}$ y Canuto Sáenz de Tejada García ${ }^{7 \mathrm{~T}}$, desde I893 hasta el final del presente estudio.

\section{I.2.4. Diputados, tesoreros, secretarios y personal al servicio del Colegio}

Los Estatutos de I834 se refieren escuetamente a los diputados, asignando al diputado $\mathrm{I}^{\mathrm{O}}$ la función de sustituir al decano en sus ausencias -art. $2 \mathrm{I}-\mathrm{y}$ al diputado $2^{\circ}$ la de vigilar la conducta de los abogados inscritos en el colegio, informando, en su caso, a la Junta de Gobierno, de las faltas que pudiesen advertirse y de las quejas recibidas relativas a «hechos que sean contra el honor de la profesión»-art. 22-. Como antes se vio, el Colegio logroñés contó con dos diputados durante buena parte del tiempo aquí analizado, no quedando constancia en las actas de incidente alguno en relación a su elección anual. Por lo que se refiere al ejercicio de sus funciones, las actas refieren la puntual intervención del diputado $\mathrm{I}^{\circ}$ que actúa como «decano accidental» durante las ausencias del decano, así como la amonestación por parte de la Junta de Gobierno a algún colegiado, que resultaría de la labor realizada por el diputado $2^{\mathrm{o} 72}$.

No mucha más información nos proporcionan los libros de actas en relación a los tesoreros, a los que encontramos, generalmente, presentando informes sobre los gastos realizados por el Colegio y las cuentas de cargo y data del ejercicio económico concluido ${ }^{73}$. Las actas reflejan asimismo la autorización al tesorero para efectuar determinados gastos y para la adquisición de ciertos efectos que se precisan para su funcionamiento ${ }^{74}$. A tenor de los Estatutos, el tesorero es el encargado de la recaudación y administración de los fondos del Colegio, debiendo llevar dos libros en los que se asienten las entradas y salidas -art. 23y rindiendo cuentas ante la Junta de Gobierno, a la que corresponde presentarlas, para su aprobación, por la Junta General del Colegio -art. 24-.

Por su parte, el secretario-contador se ocupa de recibir las solicitudes dirigidas a los órganos de gobierno de la corporación, de llevar dos libros en los que se registran las actas de las Juntas General y de Gobierno y otros dos libros de entradas y salidas iguales a los que lleva el tesorero, del registro de libramientos, de la presentación de un resumen anual de las cuentas, de la elaboración de las listas anuales de colegiados y de la expedición de certificaciones -arts. 25 y $26-$. Los libros de actas se refieren en diferentes ocasiones a

${ }^{68}$ Licenciado en derecho civil y canónico por la Universidad de Madrid en I882, ingresó en el Colegio en el año siguiente. $\mathrm{El} 7$ de junio de I89o fue elegido decano y tomó posesión el día 30. En I89i es relevado de su cargo de decano y pasa a desempeñar, sucesivamente, los de diputado $I^{\circ}$ y $2^{\circ}$ de la Junta de Gobierno, puesto que desempeña hasta el I ${ }^{\circ}$ de julio de I894.

${ }^{69}$ Pasó su examen de suficiencia en la Universidad de Salamanca el 9 de septiembre de 1874 y se le expidió el título de Licenciado en derecho civil y canónico en Madrid, el 20 de julio de I880. Ingresó en el Colegio logroñés el 8 de mayo de i884. En junio de i89i fue elegido decano, siendo relevado en I892 y desempeñando posteriormente, hasta el iو de junio de I893, el cargo de diputado $\mathrm{I}^{\circ}$.

$7^{\circ}$ Licenciado en derecho civil y canónico por la Universidad de Salamanca, se le expidió el título el 5 de septiembre de I876. En la Junta de Gobierno de 9 de agosto de 1884 se vio su solicitud de ingreso y fue aceptada. En I89I fue elegido secretario-contador y en el año siguiente decano, ocupando posteriormente el cargo de diputado $\mathrm{I}^{\circ}$ en diversas ocasiones y, accidentalmente, el de secretario-contador en I893. Falleció el 26 de enero de 1896 .

${ }^{71}$ Licenciado en derecho civil y canónico por la Universidad de Madrid, en la que demostró su suficiencia el 9 de mayo de 1878 . Se le expidió el correspondiente título el 6 de abril de i880. Se incorporó al Colegio de Abogados de Logroño en julio de I 885 y durante ese año actuó ya como secretario interino en algún momento, ocupándose, junto al decano, de la elaboración de la instancia sobre la creación de las Audiencias provinciales. En I886 es elegido secretario y en I893 decano, siendo reelegido en el año siguiente.

${ }^{72}$ Así, por ejemplo, en las sesión celebrada el 3 de septiembre de I882, ACA, Libro $1^{\circ}$ de Actas de la Junta General, s.f., acta núm. 48 y en la de

73 Ibídem, s.s., acta núm. 57, sesión de 22 de junio de I 884 .

${ }^{74}$ V.gr., ibídem, ff. 9r- ${ }^{\circ}$, acta de la sesión de I5 de diciembre de I844. 
los problemas ocasionados por su ausencia. Si en I 838 -como antes se indicó- se optó por el nombramiento de un secretario adjunto, lo más frecuente es que se proceda a la designación de un secretario interino. En I887, la Junta General trata de resolver, con carácter general, los problemas derivados de la ausencia, enfermedad, incompatibilidad o cualquier otro impedimento del secretario, acordando al efecto que «lo mismo en el actual ejercicio que $\mathrm{n}$ los sucesivos, le reemplace y sustituya con facultad de certificar cada uno de los Sres. que hayan desempeñado el cargo de Secretario principiando por el más moderno, o el Colegiado que designe en cada caso el Sr. Decano» ${ }^{75}$. El criterio de la menor antigüedad en el Colegio sirvió asimismo durante algún tiempo para determinar el ejercicio de la Secretaría, tal como refleja el acta de la sesión celebrada el 5 de junio de i88I, en la que, tras recogerse el resultado de la elección para la renovación de los miembros de la Junta de Gobierno, se especifica que no se efectuó para el cargo de secretario, «para el que según costumbre establecida, fue designado D. Franco Iriarte y Echarri, en concepto de Abogado últimamente ingresado en el Colegio». Finalmente las actas nos permiten comprobar el desempeño de las funciones de certificación, redacción de actas, etc. asignadas a los secretarios-contadores por los Estatutos.

Los Colegios podían contar además con uno o más porteros, nombrados por la Junta de Gobierno y con un escribiente «en aquellos Colegios donde la Junta general crea que debe haberlo por ser muchos los asuntos que ocurran»-art. 29-. En el caso del Colegio de Abogados de Logroño, la decisión de contar con un escribano se tomó tempranamente. En la sesión celebrada por la Junta General el 20 de septiembre de I838 se acordó, a propuesta del secretario, la contratación de un escribano «para la extensión de actas, oficios y otros quehaceres inherentes al Colegio y su Secretaría». El designado fue D. Ciriaco Cambra, a quien no se le señalaron emolumentos fijos, al considerarse que las tareas a realizar no tenían tampoco carácter regular, acordándose gratificarle «proporcionadamente su trabajo» ${ }^{76}$. En I844 consta la existencia de un empleado, al que se refieren como «avisador», que se ocupa de efectuar las notificaciones al que, probablemente, tampoco se había asignado aún en este tiempo una retribución fija ${ }^{77}$ y al que encontramos años más tarde percibiendo «la gratificación anual de quinientos reales que se le ha abonado todos los años por Navidad», precisándose en este caso que es el «encargado de hacer las citaciones y prestar cuantos servicios sean necesarios al Colegio» ${ }^{78}$. Con ocasión del fallecimiento, en I889, de quien durante años había sido el conserje del Colegio de Abogados de Logroño -D. Andrés Avelino Solano-, varios candidatos solicitaron el empleo. En su mayor parte eran empleados de la Audiencia, desempeñando en la misma los empleos de porteros, alguaciles o mozos. La Junta, reunida en el mes de mayo, resolvió nombrar conserje en propiedad del Colegio a D. Patricio Solana y Arpón -que había sido mozo de estrados de la Audiencia y que venía ejerciendo interinamente el empleo de conserje del Colegio desde el mes de febrero de ese año- señalándole un salario anual de cien pesetas ${ }^{79}$. Dos años más tarde, uno de los porteros de la Audiencia solicita la plaza de conserje del Colegio. En su instancia sostiene que estando vacante «tiene entendido que dicha plaza ha sido siempre desempeñada desde la creación de esta Audiencia por el portero de la misma, por vivir este en el mismo local en que se halla establecido el Colegio de abogados, como así sucedió mientras vivió su antecesor, D. Andrés Avelino». La Junta de Gobierno, no entra en esta última consideración, rechazando la solicitud al no estar vacante la plaza sino ocupada en propiedad por D. Patricio Solana ${ }^{8 \circ}$. Este último solicitó tres años más tarde un incremento

\footnotetext{
${ }^{75} \mathrm{Ibídem}$, acta núm. 66, sesión del I9 de junio de I887.

${ }^{6}$ Ibídem, ff. $5 \mathrm{v}-6 \mathrm{v}^{\mathrm{o}}$.

77 El acta de la sesión celebrada el i5 de diciembre de I844 indica que se autorizó al tesorero «para que hiciera las gratificaciones de costumbre al avisador», ibídem, ff. $9 \mathrm{r} y \mathrm{v}^{\mathrm{o}}$.

${ }^{8} \mathrm{Ibídem}$, s.f., acta núm. 58, sesión de $\mathrm{I}^{\circ}$ de junio de I884.

79 Ibídem, acta núm. 73 , sesión de 26 de mayo de 1889.

${ }^{80}$ Ibídem, acta núm. 79, sesión de I4 de junio de I89I.
} 
de salario, accediéndose por parte de la Junta a un aumento de veinticinco pesetas anuales, que percibiría con efectos de $\mathrm{I}^{\mathrm{o}}$ de julio de ese año ${ }^{8 \mathrm{r}}$.

\section{I.3. Funcionamiento del Colegio}

La principal función de los Colegios de Abogados era la que tocaba a la salvaguarda de la profesión, lo que pasaba por el necesario control del ejercicio de una actividad profesional con clara repercusión social ${ }^{82}$. Junto a ésta, los Estatutos de los Colegios de Abogados del Reino de I 838 atribuyen a estas corporaciones la organización del repartimiento de las causas de pobres entre los miembros del respectivo Colegio, constituyéndose en otra de las piedras angulares de la actividad de estas corporaciones curiales. Además, los Colegios atendían a otras muchas cuestiones de menor calado que resultaban imprescindibles para garantizar el buen funcionamiento de la propia institución.

\section{I.3.I. La inscripción colegial}

Los Estatutos de 1838 incluyen, tras las «Disposiciones generales», la regulación «De la admisión en los Colegios» (arts. 6-Io), en la que se contemplan los requisitos formales para su solicitud, la tramitación de la admisión por el Colegio y las causas de suspensión de la admisión, así como de la exclusión de los abogados ya inscritos.

En relación a las solicitudes se prevé que deban realizarse mediante escrito, dirigido a la Junta de Gobierno del Colegio de que se trate, acompañado del título de Abogado despachado por la correspondiente Audiencia o Tribunal, o, en su caso, de la certificación de estar inscrito en otro Colegio. Recibida la solicitud en el Colegio, era preciso obtener una acordada de la Audiencia, Tribunal o Colegio de Abogados, planteándose tempranamente la duda -resuelta por real orden de 3 de marzo de $1839^{83}$ - acerca del modo en que debía tramitarse. En I844 se dejó sin efecto esta previsión contenida en el artículo 7 de los Estatutos, disponiéndose que, tan sólo en los casos en que existiese duda acerca de la legitimidad de los títulos, se retengan y consulte lo que fuera preciso ${ }^{84}$. La decisión acerca de la admisión o no del solicitante correspondía a la Junta de Gobierno, que podía suspender la admisión hasta que el interesado removiese los obstáculos que la Junta detectase y que debía poner en su conocimiento ${ }^{85}$. A tenor del artículo 9, la Junta podía decidir la suspensión si existían dudas acerca de la legitimidad del título presentado y si se observaba cualquier impedimento legal para el ejercicio de la abogacía. Por su parte, el mencionado decreto de 6 de junio de i844 sumó a las causas de suspensión la derivada de «la falta de cualidades morales a juicio de la Junta de gobierno». La suspensión podía ser recurrida en los tribunales competentes.

Hacia el final de período aquí analizado, los requisitos exigidos para el ejercicio de la Abogacía en la Ley provisional para la organización del poder judicial, llevaron a que la documentación que debían aportar los solicitantes fuese más prolija, incluyéndose, a la luz de los diferentes expedientes que he podido consultar, la correspondiente instancia extendida en papel timbrado, la cédula personal del solicitante, el certificado de nacimiento

\footnotetext{
${ }^{81}$ Ibídem, Libro $2^{\circ}$ de Actas de la Junta de Gobierno, ff. 47-48, sesión de 26 de julio de I894.

${ }^{82}$ Sobre el control ejercido por las corporaciones gremiales y el impulso a los nuevos colegios profesionales en la primera mitad del siglo XIV, DEL SAZ, S., Los Colegios Profesionales, Madrid, Colegio de Abogados de Madrid-Marcial Pons, I996, pp. I9-32.

${ }^{8}$ CL, t. 25, año I839.

${ }^{84}$ Puede verse en Estatutos para el régimen de los Colegios de Abogados del Reino, p. 4I, nota al ar. $7^{\circ}$.

${ }^{85}$ En la sesión de la Junta de Gobierno de 22 de enero de i89i se acordó el ingreso condicionado a que en el término de 30 días se presentase el título de Licenciado o la certificación de ser individuo de otro Colegio de Abogdos «en la inteligencia de que, transcurrido dicho plazo sin presentar uno u otro documento, quedará sin efecto la incorporación acordada», en ACA, Libro $1^{\circ}$ de Actas de la Junta de Gobierno, s.f.
} 
y bautismo, el título académico requerido, un documento acreditativo de de haber abonado la cuota de ingreso en el Colegio, la declaración de alta en la contribución industrial y de comercio y una certificación de no estar incurso en ningún proceso penal o haber sido condenado a penas aflictivas ${ }^{86}$.

El Colegio de Abogados de Logroño, en una interpretación literal de lo dispuesto en el art. 6 de los Estatutos, acordó exigir a un abogado que pretendía quese le reconociese su condición de colegial que solicitase «en la debida forma» su ingreso. En cuanto a la documentación adicional, de las actas de admisión conservadas en el Archivo del Colegio se desprende con claridad que, en tanto en los primeros años de vida del Colegio, la mayor parte de los aspirantes presentó su título de Abogado expedido por los tribunales, más adelante la documentación aportada será el título de Licenciado en Derecho expedido por alguna de las universidades del Reino. En cuanto a las resoluciones, constan referencias a diferentes «suspensiones», de entre las que pueden destacarse dos discrepancias relevantes a la hora de resolver acerca de la admisión de un titulado. La primera se produjo en el momento de nacimiento del Colegio, en tanto la segunda se registró casi al final del período aquí analizado. A la primera me he referido ya anteriormente al tratar de los órganos de gobierno del Colegio. El problema se suscitó por el error cometido en la convocatoria de quienes podían tomar parte en el establecimiento del Colegio de Abogados de Logroño. La convocatoria dirigida a un abogado que no tenía estudio abierto ni residencia en la ciudad y su participación, de hecho, en la sesión de instalación y en la constitución misma de la Junta de Gobierno para la que resultó elegido, dio lugar a un dilatado enfrentamiento entre este letrado -D. Andrés Velasco- y el Colegio logroñés que éste trató de zanjar excluyéndolo de la nómina de miembros de la Corporación, como no podía ser de otra forma al no cumplir los requisitos estatutarios y al amparo de lo prevenido en el art. 9 de los mismos, al tiempo que se le ofrecía la posibilidad de incorporarse al Colegio solicitándolo formalmente, de conformidad con las previsiones de los Estatutos, y dando cumplimiento a ciertos requisitos particulares que se fijaron por la propia Junta de Gobierno. Por su parte, Velasco trató de hacer valer su condición de miembro fundador del Colegio logroñés, exigiendo la expedición de un certificado acreditativo de su participación en la sesión de instalación que la Corporación se resistía a entregarle pero que, a la postre, tuvo que poner a su disposición. En este punto, entró en escena también el Juzgado de $\mathrm{I}^{\circ}$ Instancia de Logroño, que acordó admitir los escritos de Velasco, al que promovió además como asesor del propio Tribunal, lo que llevó al Colegio a declarar -por voz de su Decano- que se estaban menoscabando las prerrogativas y el decoro de esa corporación:

«Que era notorio el desprecio con que el Sr. D. Diego Ponce de León, Alcalde Constitucional y Juez de $\mathrm{I}^{\mathrm{o}}$ Instancia interino de este Partido, miraba las prerrogativas y el decoro del Colegio, consintiendo, y aun formando empeño para que la dirección jurídica y contenciosa de todos los negocios sea asesorada por el Sr. D. Andrés Velasco, y para que sus escritos en derecho sean admitidos en el tribunal, a pesar de no ser colegiado ni poder ejercer la profesión sin el requisito de su incorporación según el Colegio lo tenía decidido con arreglo a sus estatutos, y a pesar también de habérsele comunicado la matrícula del Colegio y hechole presente que cometía un atentado contra la Ley si permitía a los no matriculados un derecho que desde la instalación de este Cuerpo no es permitido más que a los pertenecientes a él. Que por lo tanto era preciso que se buscase el medio de defensa del honor de dicho Cuerpo, de hacer respetar las leyes que lo rigen, y las determinaciones adoptadas por él con arreglo a las mismas.» ${ }^{87}$

A la declaración siguió, necesariamente, la adopción de las medidas de defensa de su posición que el Colegio estimó adecuadas. En primer término, la prudencia les hizo decidir que debía tratar de obtenerse una respuesta diferente de parte del Juzgado,

\footnotetext{
${ }^{86}$ Ver al respecto el art. 873 de la Ley sobre organización del poder judicial, de I5 de septiembre de I870.

${ }^{87}$ ACA, Libro $1^{\circ}$ de Actas de la Junta General, ff. $5 \mathrm{v}^{\circ}-6 v^{\circ}$, acta de la sesión de 20 de septiembre de I 838 .
} 
acordándose, al propio tiempo, que, si no era así, se interpusiese el recurso que en derecho cupiese ante la Audiencia territorial:

«Tomadas en consideración estas y otras reflexiones semejantes emitidas por el Sr. Presidente, se determinó que ante todas cosas se oficiase por última vez al Sr. Juez de I ${ }^{\circ}$ Instancia, reproduciendo las razones de queja que el Colegio tenía sobre su proceder, y haciéndole presente que si desde la fecha no cesaba de cometer a D. Andrés Velasco o a otro cualesquiera Abogado no colegiado las asesorías del Juzgado, y sino repelía los escritos que firmados por él presentasen las partes, le sirviese de gobierno que iba el Colegio a usar de su derecho entablando los recursos conducentes. Que pasado este oficio, y visto que el Juez lo contradecía, o no lo contestaba, inmediatamente se formalizase un recurso a la Audiencia para cuya dirección se comisionó a la Junta de Gobierno de este mismo Colegio a cuyo cargo corriese y a cuyo nombre se extendiese el correspondiente poder designando el Procurador que le pareciese, correspondiéndose con él, y haciendo entre todos los Sres. Colegiales los repartimientos que vieren ser necesarios para los gastos que irrogasen».

Al propio tiempo, convinieron en que, en tanto se resolvía la cuestión planteada con el Juzgado, ninguno de los colegiados debía consentir providencia alguna del Juzgado asesorada por letrado que no estuviese matriculado en el Colegio, ni debían tampoco contestar escrito alguno firmado por quien no lo estuviere.

«..., prometiendo bajo su fe y honor, como en efecto lo prometieron en el acto, verificarlo así, sin llevar a las partes interesadas en los negocios encomendados a su defensa derechos algunos por los escritos de no contestación o por los recursos de nulidad de aquellas providencias que se vieran precisados a entablar, puesto que todos estos escritos habían de ser ajenos del interés de sus defendidos y relativos tan solo al interés de la Corporación.

Que cada vez que en cualquier negocio se viesen comprometidos a obrar así, diesen por medio de un oficio parte al Colegio.

Que la matrícula del mismo -concluían- se comunicase a todos los tribunales de esta Capital para los mismos efectos de no admitirse el ejercicio de la profesión a los no inscritos en ella».

El enfrentamiento con Velasco y Ponce de León llegó, en efecto, a la Audiencia territorial, a la que acudieron ambos y también el Colegio de Abogados de Logroño. La resolución, cuyo tenor no conozco, llegó en I840, poco antes, pues, de que, con carácter general, se apostase de nuevo por la libertad de ejercicio y la no obligatoriedad de la colegiación. El letrado Velasco resultó finalmente incorporado al Colegio, figurando en las primeras listas de colegiados que se han conservado ${ }^{88}$.

La segunda de las grandes controversias a las que me he referido tuvo lugar en I894. El protagonista en este caso fue el letrado Cándido Urbina y Ortega cuya solicitud de admisión enfrentó al decano con el resto de la Junta de Gobierno, al considerar el primero

\footnotetext{
${ }^{88}$ En el acta de la sesión celebrada por la Junta General el I7 de octubre de I838 se hace referencia a la certificación recibida de la Audiencia de Burgos «comprensiva de las providencias que había dictado a los recursos» planteados por las partes, pero no se recoge con claridad el sentido de las mismas, ACA, Libro $1^{\circ}$ de Actas de la Junta General, ff, 6vº-7r. En ibídem, f. 8r, se inserta una diligencia en los siguientes términos: «Estando en borrón las actas de las Juntas celebradas y versando todas ellas sobre puntos pertenecientes a D. Pedro José Jalón y D. Andrés Velasco, habiendo quedado terminadas las diferencias que con estos mediaron sobre su incorporación o no en el Colegio por la real orden de 8 de febrero del presente año, no me ha parecido oportuno extenderlas, lo cual pongo por diligencia para que en todo tiempo conste. Logroño, 24 de septiembre de I840». Asimismo, en ibídem, ff. Ir y vo, «Matrícula de los Abogados pertenecientes al Colegio de esta Capital», en la que se incluyen registros hasta del año I883, está incorporado D. Andrés Velasco, sin indicación de la fecha, pero anterior en todo caso a I84I, que sería la primera de las registradas, anotándose junto a su nombre la nota aclaratoria de su fallecimiento en fecha asimismo no especificada.
} 
que no era posible al no haberse incluido entre la documentación aportada el certificado de no tener antecedentes penales a que se refería la vigente Ley provisional de Organización de los Tribunales al tratar del ejercicio de la Abogacía. Por su parte, los otros integrantes de la Junta sostuvieron que no resultaba imprescindible y que en todo caso se trataba de una prueba de carácter negativo y, como tal, difícil o incluso imposible, de cumplir. En este sentido -apuntaban- no se exige en otros Colegios ni se ha requerido nunca en el de Logroño. Concluían su argumentación señalando que conocían personalmente al solicitante y que era hombre de conducta intachable, de suerte que la exigencia de la referida certificación vendría a suponer una suerte de desprecio del mismo. El decano insistió en lo sostenido en su voto particular, sometiéndose finalmente a votación y resultando D. Cándido Urbina incorporado al Colegio con el voto mayoritario de la Junta de Gobierno ${ }^{89}$. En el año siguiente, volvieron a plantearse dudas acerca del modo en que debía acreditarse el cumplimiento de los requisitos exigidos para el ejercicio de la Abogacía, resolviéndose elevar la correspondiente consulta al Ministerio solicitando la pertinente aclaración ${ }^{90}$, así como otras tantas instancias solicitando que se limitase el número de abogados que podían ejercer el territorio de cada Colegio y que se declarase incompatible el ejercicio como abogado con el cargo de Juez municipal propietario en las capitales de provincia, o con el cargo de fiscal de los tribunales contencioso-administrativo, o con el de abogado del Estado ante los Juzgados y Tribunales y en las Oficinas de la Hacienda pública ${ }^{91}$.

\section{I.3.2. La Abogacía de pobres}

La defensa y representación de los litigantes pobres, contemplada en las ordenanzas para las Audiencias de I835 como una de las cargas que pesaban sobre abogados y procuradores, determinó que los Estatutos de i 838 atribuyesen a las Juntas de Gobierno de los Colegios la competencia para nombrar abogados de pobres, tratando de distribuir esa carga entre los colegiales de manera equitativa y a los decanos la de llevar los correspondientes turnos o repartimientos de casas de pobres. Por su parte, las Juntas Generales debían fijar los criterios o modo en que las de Gobierno efectuarían esa distribución ${ }^{92}$. El derecho a ser defendido y representado gratuitamente en los Tribunales fue asimismo recordado en este tiempo al determinar los nuevos aranceles judiciales vigentes para el año I $83^{93}$. En el año siguiente, una real orden de 20 de septiembre, dispuso -a instancia del Colegio de Abogados de Valladolid- que se doblase el número de abogados de pobres con el fin de facilitar la posibilidad de elección de defensor y evitar que ésta recaiga sobre unos mismos letrados a los que se imposibilita para «mantener con un trabajo lucrativo a sus familias» ${ }^{94}$.

Así las cosas, la ya mencionada orden de 28 de noviembre de I84I, por la que se dejaba sin efecto la obligación de inscribirse en un Colegio para poder ejercer la profesión

${ }^{89}$ ACA, Libro $2^{\circ}$ de Actas de la Junta de Gobierno, ff. 5I-57, acta de la sesión de 4 de octubre de I894.

90 Ibídem, ff. 95-Io6, acta de la sesión de 9 de noviembre de I895.

${ }^{9}$ L Los diferentes extremos apuntados fueron estudiados por la Junta de Gobierno en ibídem. Las comunicaciones al Ministerio instando la declaración de incompatibilidad se sumaban a las previamente contempladas en relación a la Notaría, ibídem, año i894.

$9^{2}$ El Título III de las Ordenanzas para todas las audiencias de la Península e islas adyacentes, «De los abogados y procuradores que actúan en las audiencias», contempla, en el art. I98, la designación con carácter anual, por parte de los Colegios, de dos o más abogados que se encargarán de la defensa gratuita de los pobres tanto en las causas criminales como en las civiles, en Gaceta de Madrid, del Jueves 3I de diciembre de i835 y ss.; Artículos I5 y I9 de los Estatutos para los Colegios de Abogados del Reino, cit.; Sobre la valoración realizada por los diferentes operadores

${ }_{93}$ Aprobados por real orden de 29 de noviembre de I837, CL, t. 23, año I837, pp. 340-342. Sobre la reacción negativa de los diferentes operadores jurídicos -jueces, relatores, secretarios, abogados y procuradores, entre otros-, BÁDENAS ZAMORA, A., El patrocinio del justiciable pobre en la España liberal (1833-1868), Madrid, Dykinson, 2005, pp. IO7-II2.

94 CL, t. 25, año I839. 
en el ámbito territorial del mismo, precisó que todos los abogados, estuviesen o no matriculados en un Colegio, debían participar de la obligación de asumir la defensa de los pobres, lo que sin duda habría complicado el procedimiento de reparto o distribución de cargas establecido tres años atrás. En la práctica, sin embargo, los Colegios de Abogados, sin perjuicio de la libertad de ejercicio, continuaron designando los abogados de pobres ${ }^{95}$, de suerte que el restablecimiento del artículo $\mathrm{I}^{\circ}$ de los Estatutos por el tantas veces mencionado real decreto de 6 de junio de I844 no introdujo mayor novedad que la de prescribir la participación del fiscal o promotor fiscal en las sesiones de la Junta en la que se llevase a cabo anualmente el nombramiento de abogados de pobres, como una garantía añadida a que «tan honroso patronato se distribuya con equidad y del modo más conveniente a la clase desvalida a que se dispensa», extremo éste que fue derogado expresamente por real decreto de $\mathrm{I}^{\circ}$ de abril de $\mathrm{I} 855^{96}$.

La obligación inexcusable de hacerse cargo de la defensa de pobres dio pie a la introducción, en I846, de exenciones fiscales en el pago de la contribución industrial, con las que se trataba de paliar la carga que aquella representaba para los diferentes operadores jurídicos y que se mantuvieron, con ciertas modificaciones, en adelante ${ }^{97}$, haciendo necesaria una reforma puntual de los Estatutos de los Colegios de Abogados con el fin de evitar las altas y bajas en la matrícula del subsidio que se producían a mitad del ejercicio económico como consecuencia de la designación de los abogados de pobres por parte de las Juntas de los Colegios de abogados en las fechas señaladas por los Estatutos ${ }^{98}$.

Correspondiendo a las Juntas generales de los Colegios, como se ha visto, la determinación de los criterios con los que las Juntas de Gobierno efectuarían anualmente la designación de los abogados de pobres, el Colegio de Abogados de Logroño resolvió, en el mes de octubre de I838, que el criterio sería la menor antigüedad en la matrícula del Colegio. Dos meses después, acordaron «que para hacer mas llevadero este gravamen no durante mas que tres meses» ${ }^{99}$, reiterándose en I840:

«Acordose que para la defensa de los pobres se siguiera el método establecido de nombrar cada tres meses un Colegial el más moderno, y que el secretario llevase el turno con toda exactitud, y que cada vez que se concluyera el trimestre se diese conocimiento por oficio al Sr. Juez de primera instancia del que se encargaba de las defensas indicadas» ${ }^{100}$.

El criterio para la elección, así como el período para el que eran designados, parece haberse abandonado poco después, conduciéndose el Colegio logroñés con arreglo a las prescripciones legales, esto es, designando dos letrados para hacerse cargo de la defensa de pobres durante el año siguiente ${ }^{\mathrm{IOI}}$. En los años siguientes, las actas nos muestran el

${ }^{95}$ En este sentido, GARCÍA GOYENA, F. y AGUIRRE, J., Febrero o librería de jueces, abogados y escribanos, Madrid, I. Boix, editor, I842, V, p. 245, en BÁDENAS ZAMORA, A., op. cit., p. 85.

${ }_{9}^{6} C L$, t. 47, año I855, p.396. Sobre la reacción de los Colegios de Abogados ante lo que, sin duda, se había visto como un intento de controlar o limitar su independencia, PÉREZ BUSTAMANTE, R., op.cit., p. 294 y BÁDENAS ZAMORA, A., op.cit., pp. I39-I40.

${ }_{97}$ Real orden de 19 de julio de 1846 , prescribiendo reglas para la exención del pago del subsidio industrial a los relatores, escribanos, abogados y procuradores de los tribunales y juzgados que se ocupan en negocios de pobres y criminales, en $C L$, t. 38, pp. 96-98.

$9^{8}$ Real decreto de 3 de abril de i868, reformando el art. II de los Estatutos de los Colegios de Abogados, relativo a la celebración de su Junta general y nombramiento de Abogados de pobres, en ibídem, t. 6o, año I868, pp. 378-379. 1838 .

99 ACA, Libro $1^{\circ}$ de Actas de la Junta General, ff. $6 v^{\circ}-7 \mathrm{r}$ y $7 v^{\circ}-8 \mathrm{r}$, sesiones de I7 de octubre y 22 de diciembre de

Ioo Ibídem, ff. 8r-v, acta de la sesión de I8 de diciembre de I840.

${ }^{\text {Ior }}$ El acta refleja que se presentaron dos voluntarios y se indica que están exentos, conforme a la ley, del pago de la cuota de la contribución industrial, ibídem, ff. $9 v^{\circ}$-Ior, sesión de 22 de diciembre de I846. EnI880, sin embargo, la situación parece haber cambiado, toda vez que uno de los letrados «manifestó su deseo de trabajar 
pormenor de las designaciones, indicando que los dos abogados nombrados alternarían en las causas civiles y criminales, ocupándose el decano de llevar el turno, resolviendo que en los casos de incompatibilidad de alguno de ellos o cuando hubiese necesidad de más abogados para la defensa de los pobres se alternarían las causas «entre todos los demás, principiando por los más modernos; como estaba establecido anteriormente, designándose también el turno por el decano» ${ }^{102}$. Asimismo los encontramos haciéndose cargo, pese al reparo manifestado expresamente al respecto, de dos causas criminales remitidas por el Juzgado de Calahorra, cuya defensa se encomienda a los abogados encargados de la de pobres $^{\mathrm{I03}}$, debatiendo sobre la necesidad de respetar los turnos establecidos ${ }^{\mathrm{IO}}$, o viéndose obligados a designar a un tercer letrado para hacerse cargo de la defensa de los pobres al haber manifestado los dos previamente nombrados que el asunto que se les había encomendado resultaba indefendible y estimar el fiscal de la Audiencia de lo Criminal que sí lo era. En este punto, el Colegio manifestará su malestar por la falta de motivación del dictamen fiscal, señalando que no sólo «era racional, conveniente y necesario que se consignasen dichas razones, tanto porque los dictámenes de cualquier clase que sean deben siempre fundarse, cuanto para que sirviese de ilustración al tercer Abogado que se nombrase en turno» y resolverá comunicarlo al juez de primera instancia del partido al objeto de que se instase al fiscal a razonar su dictamen ${ }^{\text {105 }}$.

La mayor complejidad procedimental en las causas criminales llevó a que el Colegio de Abogados de la capital riojana lamentara las graves dificultades que tenía para atender a la defensa de todos los procesados pobres de la provincia, acordándose designar una Comisión integrada por el secretario y el vocal $2^{\circ}$ de la Junta de Gobierno «para que estudiaran la proposición de medios y se encargaran de redactar la exposición que habrá de dirigirse al Sr. Ministro de Gracia y Justicia y circularse impresa a todos los Colegios de Abogados, periódicos profesionales y políticos, y a cuantos Centros pudiesen coadyuvar al buen éxito de petición tan justa». Los comisionados cumplieron su misión en apenas un mes, sin que quede constancia en las actas de la repercusión que pudo tener la misma ni del alcance de la difusión que finalmente se le dio ${ }^{\text {ro6 }}$.

\section{I.3.3. Otras cuestiones tocantes al funcionamiento del Colegio}

Sin duda una cuestión que preocupa desde el comienzo y de manera reiterada a los integrantes del Colegio será la falta de unas dependencias propias en las que puedan quedar instalados de manera permanente los escasos enseres de los que va dotándose, poco a poco, para su correcto funcionamiento. Habiéndose celebrado la sesión de instalación del Colegio en una de las salas de la Diputación Provincial que tuvo a bien cederla interinamente para esa reunión, no consta dónde tuvo lugar la segunda de las reuniones y se recoge, ya en la tercera, la necesidad de contar con un local propio, algo que el Colegio no verá resuelto hasta la instalación en Logroño de la Audiencia de lo Criminal en cuya sede se habilitaron de forma estable las dependencias correspondientes al Colegio de Abogados. Será, pues, a partir de 1883 cuando el Colegio comience a reunirse en sus nuevas instalaciones, habiéndolo hecho hasta la fecha en el domicilio de los decanos o de otros de

como Abogado de pobres siempre que obtuviera gratuita la matrícula de subsidio y contara con la cooperación de algún compañero», a lo que se respondío -según consta en el acta- que se harían las gestiones pertinentes con la administración de Hacienda pública, ibídem, s.f., acta núm. 42.

${ }^{\text {Io2 }}$ Ibídem, ff, IIr y v ${ }^{\circ}$, acta de la sesión de 30 de diciembre de I848.

${ }^{\text {I03 }}$ El acta de la sesión de I4 de octubre de 1873 recoge a la letra la salvedad que se hace del derecho del Colegio a recurrir la providencia del Juzgado de Calahorra, sin perjuicio de que se encomiende la defensa a los dos abogados de pobres para no retardar la administración de Justicia, ibídem, ff, $26 r-v^{\circ}$.

${ }^{104}$ Ibídem, diversas actas de las sesiones celebradas en I894 muestran discrepancias en relación a los turnos.

${ }^{105}$ Ibídem, s.f., acta núm. 70, sesión de 6 de enero de I888.

${ }^{106}$ Ibidem, s,f., acta núm. 49, sesión de 3I de diciembre de I882. 
los individuos que en cada momento integraron la Junta de Gobierno, en alguna dependencia de la nueva casa municipal -en el año I872- o en la sala del Juzgado municipal -a partir de I880-. Poco después de haberse instalado en la sede de la Audiencia, parece preocuparles la necesaria adecuación del salón de sesiones del Colegio, facultándose a la Junta de Gobierno entrante para que procurase esa instalación más adecuada.

Tempranamente el Colegio fue dotándose de algunos enseres -papel, escribanía, togas y birretes, etc. - necesarios para el desarrollo de su actividad. La falta de un local propio impedía, sin embargo, la instalación de manera adecuada del archivo de la corporación y la formación de una biblioteca ${ }^{\mathrm{IO} 7}$. Instalados en su sede en la Audiencia, en los años siguientes se observa un creciente interés por adquirir libros, sobre todo de derecho penal y colecciones de sentencias del Tribunal Supremo en materia criminal ${ }^{108}$. Se adquieren asimismo una estufa, material de oficina, e incluso se muestra interés por la ubicación de un cuadro de los señores representantes de los diferentes Colegios que asistieron a la asamblea de abogados celebrada en la Real Academia de Jurisprudencia y Legislación en I893.

Para hacer frente a esos gastos y a los correspondientes al abono de las retribuciones de los dependientes del Colegio, éste contaba con un reducido presupuesto cuya principal capítulo de ingresos eran las cuotas de los colegiados y los derechos obtenidos por el bastanteo de poderes ${ }^{\mathrm{Io9}}$. La Junta General acordó en I848 -apremiada por la necesidad de reunir fondos para atender a las necesidades del Colegio- «que cada Colegial cobrara cuatro reales por cada poder que bastanteara en lo sucesivo y los entregara al tesorero, a lo que todos se comprometían bajo su palabra de honor» ${ }^{\text {IIO }}$. Sin duda la cuestión más tratada en lo que se refiere al presupuesto y cuentas del Colegio fue la determinación de la cuantía de la cuota de ingreso. En la sesión de I8 de agosto de 1838 acordaron que cada abogado que solicitase su incorporación al Colegio de Logroño debería abonar media onza con el objeto de compensar el esfuerzo realizado por los que habían constituido la Corporación ${ }^{\text {III }}$. Las cuotas abonadas por los nuevos colegiados irían así conformando un fondo propio del Colegio con el que hacer frente a sus necesidades. Sin embargo, en I848, la Junta deberá reconocer que no se ha llevado a efecto el acuerdo mencionado, por lo que se carece de dicho fondo ${ }^{\text {II2 }}$. En I854 la cuota de ingreso se fijó en cuatrocientos reales ${ }^{\mathrm{II}}$, en tanto en $\mathrm{I} 878$ ascendía a cien pesetas, quedando reducido, en el año siguiente, a veinticinco y volviendo a elevarse a cien en el tiempo en que fue preciso atender a los gastos extraordinarios derivados de la instalación en la nueva sede de la Audiencia $^{\text {II4 }}$.

${ }^{107}$ Sobre el archivo de la documentación y la necesidad de ir formando una biblioteca, ibídem, ff. $27 \mathrm{v}^{\circ}-28 \mathrm{r}$, acta de la sesión de la Junta General de 30 de junio de I878 y acta núm. 77, sesión de 30 de junio de I890 en la que se indica que «el archivo del Decanato, que lo forman los libros de turnos, de asuntos civiles y criminales, varios documentos impresos y el sello del Colegio».

${ }^{108}$ Ibídem, acta núm. 50, sesión de 2I de enero de 1883.

${ }^{\text {Io9 }}$ Real orden de 23 de marzo de I85i, mandando que no se admitan poderes en los tribunales de la Corte que no tengan el bastanteo del Colegio de Abogados y que la Junta de Gobierno del mismo perciba una cantidad por ellos y a qué debe aplicarla, en CL, t. 43, pp. 42I-423. Por lo que se refiere a las percepciones obtenidas por este concepto por el Colegio logroñés, ver las actas de las reuniones de la Junta General celebradas en I848 y I885, en ACA, Libro1 ${ }^{\circ}$ de Actas de la Junta General, s.f

Iı Ibídem, ff. Ior $\mathrm{y} \mathrm{v}^{\mathrm{o}}$, acta de la sesión de I7 de marzo de I848.

III Ibídem, ff. $4 \mathrm{v}^{\mathrm{o}}-5 \mathrm{r}$.

II2 Ibídem, ff. Ior $\mathrm{y} \mathrm{v}^{\circ}$, acta de la sesión de I7 de marzo de I848.

${ }^{\text {II3 }}$ Ibídem, f. I4 $\mathrm{V}^{\mathrm{o}}$, acta de la sesión de I8 de junio.

${ }^{\text {II }}$ Ibídem, Libro $1^{\circ}$ de Actas de la Junta de Gobierno, ff. $2 \mathrm{IV}^{\mathrm{O}}$-22r y $24 \mathrm{r}$, sesiones de 3 de mayo de I878 y de 26 de enero de I88I y Libro1 $^{\circ}$ de Actas de la Junta General, s.f., acta núm. 49, sesión de 3I de diciembre de I882. 
Las actas reflejan asimismo los resultados de la labor desarrollada por el tesorero y el secretario-contador, a los que correspondía llevar las cuentas de la corporación, informando puntualmente de los gastos, proponiendo las medidas necesarias para afrontar gastos extraordinarios y elaborando los presupuestos y relaciones de cuentas que anualmente se sometían a la aprobación de los órganos de gobierno del Colegio ${ }^{\text {III }}$.

El Colegio de Abogados de Logroño no contó -durante el período aquí considerado- con unos Estatutos propios, por lo que la primera de sus «Disposiciones de gobierno interior» establecía que «El Ilustre Colegio de Abogados de Logroño, no teniendo Reglamento especial, se rige por los Estatutos generales de la Nación». En I887, el Colegio constaba con otras cinco disposiciones de gobierno interior, en las que se regulaba la forma en que debían formularse las solicitudes de inscripción el Colegio, el establecimiento de cuotas extraordinarias acordadas por la Junta General y de cuyo reparto se encarga la Junta de Gobierno, la obligación de participar en los turnos de la Abogacía de pobres, la exclusión de los colegiados que no contribuyan al sostenimiento y las cargas del Colegio y la habilitación de letrados no inscritos para su actuación ante los Tribunales ${ }^{\mathrm{II} 6}$.

Finalmente, cabe señalar que las actas de las sesiones de los órganos de gobierno del Colegio de Abogados de Logroño nos permiten conocer la relación que mantiene con otras instituciones -otros Colegios de Abogados, diferentes Tribunales, Ministerio de Gracia y Justicia, etc. -y su presencia como Corporación en determinados actos públicos a los que concurre representado por su decano o por los individuos de la Junta de Gobierno. La enumeración de las referencias en las actas a cuestiones protocolarias y a las relaciones del Colegio con otras instituciones resultaría muy prolija. Sirva, así, por todas, la de la sesión de 5 de junio de $189^{\text {Ir7 }}$ en la que se refleja la tensa relación que se vivía en ese momento con la Audiencia por lo que el Colegio consideraba una apuesta por la disminución del derecho de defensa, entorpeciendo «el libre, noble y sacratísimo ministerio del Abogado que concurre a estrados a cumplir con su elevada misión».

\section{Relación de colegiados (I838-I895) ${ }^{\mathrm{II} 8}$}

\begin{tabular}{|c|c|c|c|}
\hline 1855 & AGUILLO, Lorenzo & 1853 & MARTÍNEZ RUIZ, Manuel \\
\hline $\mathrm{I} 845$ & ALBARELLOS, Eugenio & 1866 & MEDRANO, Pío \\
\hline \multirow[t]{2}{*}{$\mathrm{I} 872$} & ALVAREZ MUNILLA, Ambrosio & & MICHEL, Manuel \\
\hline & AMUSCO, Luis & 1852 & MICHEL Y OSMA, Gabino \\
\hline I867 & ANGULO, Salvador & 1887 & MONTERO Y AGUIRRE, Pedro \\
\hline I848 & APELLÁNIZ OLÓZAGA, José & I85I & MONTOYA, Manuel María \\
\hline 1845 & APELLÁNIZ RUBIO, Francisco & 1857 & MONTURUS, Pedro \\
\hline 1890 & ARAGÓN BARRÓN, Salvador & 1862 & MORALES ALBO, Federico \\
\hline ¿1853? & ARAMAYONA, Francisco & I854 & MORENO DE TORO, Cayetano \\
\hline ¿I848? & ARIAS ECHEVARRÍA, Juan & I848 & MUÑOZ, Bonifacio \\
\hline 1859 & ARIAS FERNÁNDEZ, Félix & 1889 & MUÑOZ MARTÍNEZ, Alfredo \\
\hline
\end{tabular}

${ }^{\text {II5 }}$ En ibídem, Libro $^{\circ}$ de Actas de la Junta General, acta núm. 57, sesión de 22 de junio de I884. Presentación por el tesorero de las partidas de cargo y data correspondiente al ejercicio económico y aprobación «en todas sus partes» por la Junta General, «quedando a disposición del Colegio un saldo de doscientas pesetas». En el acta de la sesión de ig de julio de 1878 (ff. $28 \mathrm{r} \mathrm{y} \mathrm{v}^{\circ}$ ) se hace referencia al relevo al frente de la Tesorería, indicándose que el nuevo tesorero «dijo haberse hecho cargo de los fondos pertenecientes al Colegio y que existían en poder de la testamentaría del finado tesorero D. Ezequiel Lorza».

${ }^{116}$ ACA, Lista de los abogados del Ilustre colegio de Logroño: fundado en 8 de agosto de 1838 de los letrados inscritos en los partidos judiciales de la provincia y de los procuradores de esta capital. Logroño, I888. Impr. De Francisco Martínez, a cargo de Pío Azagra.

${ }^{\text {Ir7 }}$ ACA, Libro $1^{\circ}$ de Actas de la Junta General, s.f., acta núm. 83.

${ }^{\text {II8 }}$ Elaboración propia a partir de los datos contenidos en ibídem, en Relación de abogados en ejercicio hasta $1888 / 89$ y en los libros de actas de la Junta General y la Junta de Gobierno del Colegio conservados en el ACA. 


\begin{tabular}{|c|c|c|c|}
\hline I854 & ARNAIZ, Bartolomé & & OCÓN ROBRES, Toribio \\
\hline $\mathrm{I} 884$ & ARROYO Y SALCEDO, Martín & 1838 & ORDOYO, José \\
\hline 1838 & ATAURI, Policarpo & & ORETA, Valentín \\
\hline 1883 & AYALA Y GIL, Zacarías & I8973 & OSÉS, Juan Antonio \\
\hline ¿亡89o? & BARRÓN Y VERDE, Pablo & I89I & PANCORBO MURO, Enrique \\
\hline I894 & BLANCO CODES, Isidro & 1838 & PLANZÓN, Celso \\
\hline 1885 & BORAU Y GARCÍA, Benito & 1878 & PLANZÓN, Juan Bautista \\
\hline 1853 & BRAVO, Francisco Félix & I888 & RAMÓN SÁENZ, Carmelo \\
\hline 1883 & BUJANDA GONZÁLEZ MATEO, Juan P. & 1885 & RAMOS, Manuel \\
\hline 1852 & CABELLO, Juan & I884 & RAMOS Y LUELMO, Eladio \\
\hline 1848 & CEBALLOS, Manuel María & 1838 & RAUMEL, Rafael María \\
\hline 1892 & CRESPO AYENSA, Rufino & I848 & RIVAS, Prudencio \\
\hline 1853 & CRESPO CRESPO, Guillermo & & ROBRES, Marcos \\
\hline 1857 & DE GAONA, Damián & I89I & RODRÍGUEZ SÁENZ DE SANTAMARÍA, José \\
\hline I857 & DE MIGUEL Y GUARRO, Juan Manuel & I884 & RODRÍGUEZ SANTAMARÍA, José \\
\hline 1862 & DELGADO, Justo Tomás & & ROYO, Ángel \\
\hline I838 & DELGADO, Tomás & 1838 & RUIZ, Salustiano \\
\hline \multirow[t]{3}{*}{1844} & DÍEZ MONFORTE, Juan Antonio & 1890 & SACRISTÁN CASCUDO, Florentino \\
\hline & ESPAÑA, Bernabé & I85I & SAENZ DE CENZANO, Vicente \\
\hline & ESPAÑA PUERTA, José & I845 & SAENZ DE TEJADA, José María \\
\hline I883 & EULATE MOREDA, Rafael & I85I & SAENZ DE TEJADA, Higinio \\
\hline 1852 & FÁRIAS HERCE, Pedro Rufino & 1885 & SÁENZ DE TEJADA Y GARCÍA, Canuto \\
\hline 1864 & FARÍAS MERINO, Joaquín & & SAENZ MOROS, Juan José \\
\hline 1879 & FÁRIAS MERINO, Julio & 1892 & SAGASTA, Canuto \\
\hline \multirow[t]{2}{*}{ ¿ $1846 ?$} & FERNÁNDEZ, Sebastián & I838 & SALVADOR SAENZ, Tadeo \\
\hline & FERNÁNDEZ DE ARELLANA, Agustín & I87I & $\begin{array}{l}\text { SALVADOR SAENZ Y SÁENZ RODRIGÁÑEZ, } \\
\text { Miguel }\end{array}$ \\
\hline 1852 & FERNÁNDEZ DE URRUTIA, Vicente & I85I & SAN MILLÁN, Ildefonso \\
\hline I884 & FERNÁNDEZ HEREDIA, Ricardo & 1850 & $\begin{array}{l}\text { SÁNCHEZ CLARES Y MANRIQUE, Enrique } \\
\text { María }\end{array}$ \\
\hline I883 & FERNÁNDEZ URRUTIA Y SOLA, José María & & SÁNCHEZ SALVADOR, Mariano \\
\hline I84I & GARCÍA TERÁN, Ricardo & $\mathrm{I} 884$ & SANJUAN E IBARRA, Melchor \\
\hline 1882 & GIL Y MARQUINA, Rafael Pedro & I848 & SANTA MARÍA, Pedro \\
\hline I85I & GOLMAYO ZUPIDE, Celso & 1867 & SANTOLALLA, Laureano \\
\hline I838 & GÓMEZ, Manuel & 1850 & SEVILLA, Agustín \\
\hline I838 & GONZÁLEZ DEL CASTILLO, Claudio & I875 & SICILIA Y MIGUEL, Ildefonso \\
\hline $\mathrm{I} 884$ & GONZALO MARTÍNEZ, Guillermo & 1890 & TEILLONA GARAY, José \\
\hline 1892 & GUTIÉRREZ LÓPEZ, Luciano & I89I & TENGANI RODRÍGUEZ, Pablo \\
\hline 1859 & HERNÁNDEZ, Ambrosio & 1878 & TORRES MÚÑOZ, Isidro \\
\hline I894 & ÍÑIGUEZ CARRERAS, Isidro & I843 & TREVIJANO, Vicente \\
\hline I88I & IRIARTE Y ECHARRI, Franco & I894 & URBINA ORTEGA, Cándido \\
\hline \multirow[t]{2}{*}{1869} & IZCO, Demetrio & 1838 & URTUZAR, Luciano \\
\hline & JALÓN, Pedro José & 1887 & VALGAÑON Y ROMERO, Tadeo \\
\hline 1883 & LACALLE Y GÓMEZ, Teótimo & 1838 & VELASCO, Andrés \\
\hline I89I & LAGUARDIA ECHEZARRETA, Atilano & ¿1862? & VELASCO, Emeterio \\
\hline I86I & LEÓN AZPEITIA, José & ¿I862? & VELASCO, Florentino \\
\hline I838 & LORZA Y LACALLE, Ezequiel & I859 & VIAR E IÑIGUEZ DE BILOLAZA, Leonardo \\
\hline 1838 & LUCIO GARCÍA, Ángel & 1838 & VIAR Y CHASCO, Leonardo \\
\hline I843 & MAGUEROS, Gregorio & 1892 & VILLARÍAS BLANCO, José \\
\hline I838 & MAGUNA, Emeterio & I878 & YERRO Y MUNTIÓN, Simeón \\
\hline I854 & MARÍN DE TORO, Cayetano & I892 & ZUGARRAMURDI VELASCO, Justo \\
\hline $\mathrm{I} 848$ & MARTÍNEZ DE ARENZANA, Román & & \\
\hline
\end{tabular}

